\title{
Identification and functional characterization of the chloride channel gene, GsCLC-c2 from wild soybean
}

Peipei Wei ${ }^{1 \dagger}$, Benning Che ${ }^{1 \dagger}$, Like Shen ${ }^{2 \dagger}$, Yiqing Cui ${ }^{1}$, Shengyan $\mathrm{Wu}^{1}$, Cong Cheng ${ }^{1}$, Feng Liu ${ }^{1}$, Man-Wah Li ${ }^{3}$, Bingjun $\mathrm{Yu}^{1 *}$ and Hon-Ming Lam ${ }^{3^{*}}$ (D)

\begin{abstract}
Background: The anionic toxicity of plants under salt stress is mainly caused by chloride $\left(\mathrm{Cl}^{-}\right)$. Thus $\mathrm{Cl}^{-}$influx, transport and their regulatory mechanisms should be one of the most important aspects of plant salt tolerance studies, but are often sidelined by the focus on sodium $\left(\mathrm{Na}^{+}\right)$toxicity and its associated adaptations. Plant chloride channels (CLCS) are transport proteins for anions including $\mathrm{Cl}^{-}$and nitrate $\left(\mathrm{NO}_{3}{ }^{-}\right)$, and are critical for nutrition uptake and transport, adjustment of cellular turgor, stomatal movement, signal transduction, and $\mathrm{Cl}^{-}$and $\mathrm{NO}_{3}{ }^{-}$ homeostasis under salt stress.

Results: Among the eight soybean CLC genes, the tonoplast-localized $c 2$ has uniquely different transcriptional patterns between cultivated soybean N23674 and wild soybean BB52. Using soybean hairy root transformation, we found that GsCLC-c2 over-expression contributed to $\mathrm{Cl}^{-}$and $\mathrm{NO}_{3}{ }^{-}$homeostasis, and therefore conferred salt tolerance, through increasing the accumulation of $\mathrm{Cl}^{-}$in the roots, thereby reducing their transportation to the shoots where most of the cellular damages occur. Also, by keeping relatively high levels of $\mathrm{NO}_{3}{ }^{-}$in the aerial part of the plant, GsCLC-c2 could reduce the $\mathrm{Cl}^{-} / \mathrm{NO}_{3}{ }^{-}$ratio. Wild type GsCLC-c2, but not its mutants (S184P, E227V and

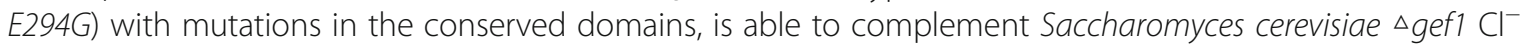
sensitive phenotype. Using two-electrode voltage clamp on Xenopus laevis oocytes injected with GsCLC-c2 cRNA, we found that $\mathrm{GsCLC}-\mathrm{c} 2$ transports both $\mathrm{Cl}^{-}$and $\mathrm{NO}_{3}{ }^{-}$with slightly different affinity, and the affinity toward $\mathrm{Cl}^{-}$ was pH-independent.
\end{abstract}

Conclusion: This study revealed that the expression of GsCLC-c2 is induced by NaCl-stress in the root of wild soybean. The tonoplast localized $\mathrm{GsCLC}-\mathrm{c} 2$ transports $\mathrm{Cl}^{-}$with a higher affinity than $\mathrm{NO}_{3}{ }^{-}$in a pH-independent fashion. GsCLC-c2 probably alleviates salt stress in planta through the sequestration of excess $\mathrm{Cl}^{-}$into the vacuoles of root cells and thus preventing $\mathrm{Cl}^{-}$from entering the shoots where it could result in cellular damages.

Keywords: Chloride, Chloride channels, CLCs, Differential expression, GsCLC-c2, Nitrate, Salt stress, Soybean, Wild soybean

\section{Background}

Salinization of irrigation water and soil is one of the most serious environmental factors limiting crop productivity

\footnotetext{
*Correspondence: bjyu@njau.edu.cn; honming@cuhk.edu.hk

${ }^{\dagger}$ Peipei Wei, Benning Che and Like Shen contributed equally to this work.

'Laboratory of Plant Stress Biology, College of Life Sciences, Nanjing

Agricultural University, Nanjing, China

${ }^{3}$ Center for Soybean Research of the State Key Laboratory of

Agrobiotechnology and School of Life Sciences, The Chinese University of

Hong Kong, Shatin, Hong Kong, China

Full list of author information is available at the end of the article
}

worldwide [1-3]. Sodium chloride $(\mathrm{NaCl})$ is the most common salt found in saline soil. It hinders plant growth not only through ionic toxicity but also by causing water deficit inside the plant, i.e. osmotic stress, and imbalance or deficiency of other ions such as potassium $\left(\mathrm{K}^{+}\right)$and nitrate $\left(\mathrm{NO}_{3}{ }^{-}\right)$[4-6]. Plants developed different strategies to combat salt stress, including exclusion or compartmentalization of ions to reduce cytosolic $\mathrm{Na}^{+}$and $\mathrm{Cl}^{-}$, especially in the aerial parts $[7,8]$. Generally, crops such as cotton, rice and barley are more sensitive to $\mathrm{Na}^{+}$than $\mathrm{Cl}^{-}$, whereas tobacco, grape,

(c) The Author(s). 2019 Open Access This article is distributed under the terms of the Creative Commons Attribution 4.0 International License (http://creativecommons.org/licenses/by/4.0/), which permits unrestricted use, distribution, and 
potato, citrus and cultivated soybean, in which salt stress effects are mainly caused by $\mathrm{Cl}^{-}$, are known as " $\mathrm{Cl}^{-}$-sensitive" or " $\mathrm{Cl}^{-}$-hating" plants [8-15]. So far, researches on the physiological and molecular mechanisms of salt tolerance in plants have mostly focused on $\mathrm{Na}^{+}$toxicity and adaptations. However, until recently, the salt injury caused by $\mathrm{Cl}^{-}$has been largely ignored [11, 14].

$\mathrm{Cl}^{-}$, as one of the essential micronutrient elements, is one of the main anions in plant cells besides $\mathrm{NO}_{3}{ }^{-}$, and is normally accumulated to macronutrient levels for enhancing plant growth and development. $\mathrm{Cl}^{-}$is involved in photosynthesis by stabilizing the water splitting system or oxygen-evolving complex of photosystem II (PSII), and also in stomatal movement, cellular osmotic pressure maintenance, electrical charge balance, turgor and $\mathrm{pH}$ regulation, nitrogen use efficiency, water-holding capacity and disease resistance [5, 14-16]. Chloride deficiency leads to reduced plant growth and symptoms such as leaf chlorosis [15]. Despite its beneficial roles in plant nutrition, $\mathrm{Cl}^{-}$can be a major toxic element in the cytosol when plants are grown in salt-affected soils, where $\mathrm{Cl}^{-}$is predominant and can accumulate in excess in the shoot/leaf, adversely affecting plant growth $[6$, 15]. During salt stress, the effects of $\mathrm{Cl}^{-}$can be additive or synergistic to those of $\mathrm{Na}^{+}$[11]. Excessive amounts of $\mathrm{Cl}^{-}$can lead to decreased uptake of $\mathrm{NO}_{3}{ }^{-}$, which is the most important nitrogen source for plants and the main monovalent anion in plant tissues and cells next to $\mathrm{Cl}^{-}$ $[14,17,18]$. Both $\mathrm{NO}_{3}{ }^{-}$and $\mathrm{Cl}^{-}$are monovalent anions with similar ionic radii, and perform a similar role in maintaining cellular charge balance and turgor, and can often be transported by the same proteins [11]. To combat $\mathrm{Cl}^{-}$/salt stress in plants, an increased $\mathrm{NO}_{3}{ }^{-}: \mathrm{Cl}^{-}$ratio in the tissues or organs, similar to the well-described increased $\mathrm{K}^{+}: \mathrm{Na}^{+}$ratio in shoots, can play a positive role $[9,14,19,20]$. Although chloride is a beneficial micronutrient in its own right and not simply a "cheap osmoticum" for plants [15], its impacts on plants under salt stress are problematic [11]. The nature of $\mathrm{Cl}^{-}$toxicity or the mechanisms of $\mathrm{Cl}^{-}$transport and detoxification during salt stress is far from being understood to such degrees as those of $\mathrm{Na}^{+}[14,21]$. Despite the general lack of information, a few reports have suggested that the control of $\mathrm{Cl}^{-}$transport from roots to shoots or the ability to maintain a low $\mathrm{Cl}^{-}$level in shoots is the key determinant of $\mathrm{Cl}^{-} /$salt tolerance in plants $[8,10,12]$. In the past few years, effects of $\mathrm{Cl}^{-}$toxicity and functions of some essential $\mathrm{Cl}^{-}$transporters, such as the chloride channel proteins (CLCs), that mediate $\mathrm{Cl}^{-}$transport and homeostasis in plants under salt stress are drawing increasing research interests $[11,15]$.

Currently, CLC genes have been identified in the genome of higher plants including Arabidopsis, tobacco, rice, potato, citrus, soybean, maize, and poplar with 7-8 gene members in each species (summarized in [21, 22]). In total, 217 homologous CLC protein or gene sequences belonging to 34 species of plants have been retrieved from the Pfam database (http://pfam.xfam.org/), Uniprot database (http://www.uniprot.org/), and NCBI database [22, 23]. The large number of plant CLC proteins, with their dual functions of $\mathrm{NO}_{3}{ }^{-}$and $\mathrm{Cl}^{-}$transport, and the differences in their respective affinity for $\mathrm{NO}_{3}{ }^{-}$or $\mathrm{Cl}^{-}$pose a degree of technical difficulties and uncertainties in the results from in-depth researches [24-26].

The genetic diversity between cultivated crops and their wild relatives provides rich resources for trait and gene discovery that have yet to be sufficiently utilized. The cultivated soybean (G. $\max$ ) is the most important legume crop in the world, offering high-quality protein and oil for human food and animal feed [27]. When exposed to $\mathrm{NaCl}$ stress, $\mathrm{Cl}^{-}$in soybean plants is usually accumulated to a toxic level in the shoots ahead of $\mathrm{Na}^{+}$. Our previous work suggested that although both $\mathrm{Na}^{+}$and $\mathrm{Cl}^{-}$are toxic to soybean under salt stress, there are differences between the sensitivity to $\mathrm{Na}^{+}$and $\mathrm{Cl}^{-}$for G. $\max$ and G. soja (the wild soybean) $[8,12,28] . \mathrm{Cl}^{-}$toxicity is more deleterious than $\mathrm{Na}^{+}$to the cultivated soybean and the damage is positively related to the $\mathrm{Cl}^{-}$contents within the leaves and stems, whereas the wild soybean and its hybrids with the cultivated soybean have stronger $\mathrm{Cl}^{-}$tolerance than the cultivated soybean itself $[8,12,28]$.

GmCLC1 (GenBank accession: AY972079; Phytozome database: Glyma.05G077100) encodes a tonoplast-localized and $\mathrm{pH}$-dependent $\mathrm{Cl}^{-} / \mathrm{H}^{+}$antiporter, which was upregulated by $\mathrm{NaCl}$ or dehydration stress, and GmCLC1-transgenic tobacco BY-2 cells displayed enhanced $\mathrm{NaCl}$ tolerance through increased $\mathrm{Cl}^{-}$transport from the cytoplasm into the vacuole [29, 30]. Our prior study also found that GmCLC1-transgenic Arabidopsis thaliana and $G m C L C 1$-overexpressing soybean hairy roots had enhanced $\mathrm{Cl}^{-}$/salt tolerance by reducing the $\mathrm{Cl}^{-}$ accumulation in shoots or by sequestering more $\mathrm{Cl}^{-}$in roots [21]. The survival rate of GmCLC1-transgenic $\triangle$ gef1 mutant yeast cells was also increased under varied levels of $\mathrm{Cl}^{-}$/salt stress [21]. Based on published GmCLC1 information and public databases, we found seven other homologous $C L C$ members, $b 1, b 2, c 1, c 2, d 1, d 2$ and $g$, in the soybean genome in both wild and cultivated soybean [22].

In this work, all the homologous soybean $C L C$ members were cloned from the $\mathrm{Cl}^{-}$-sensitive G. max cultivar N23674 and the $\mathrm{Cl}^{-}$-tolerant G. soja accession BB52. By examining their expressions under favorable or $\mathrm{NaCl}$-treated conditions, we isolated GsCLC-c2, which is the only CLC member having non-synonymous changes between $G$. $\max$ N23674 and G. soja BB52. We have also systemically investigated its functions using hairy root-composite soybean plants, site-directed mutagenesis (SDM)-mediated yeast mutant complementation, and electrophysiological assays with Xenopus laevis oocytes. Our goal is to decipher the 
molecular and physiological roles of $G s C L C-c 2$ in soybean $\mathrm{Cl}^{-} /$salt stress adaptations, so as to provide an important theoretic basis for improving $\mathrm{Cl}^{-}$/salt tolerance in soybean and other crops.

\section{Results}

Whole-genome analyses of CLC homologous genes in G. max and G. soja

Using the Phytozome database (https://phytozome.jgi. doe.gov/pz/portal.html), we have previously found seven homologs of GmCLC (Glyma.16G057600, Glyma.19G 089800, Glyma.09G157900, Glyma.16G208400, Glyma. 01G239000, Glyma.11G004600 and Glyma.13G161800) in the soybean genomes of both wild and cultivated soybeans, and named them $b 1, b 2, c 1, c 2, d 1, d 2$ and $g$ [22]. Here we extracted total RNA from the roots, stems and leaves of G. max cultivar N23674 and G. soja accession BB52 15-day-old seedlings, produced cDNAs by reverse transcription of mRNAs, and successfully cloned these seven new CLC homologs. These eight soybean CLC homologs (including GmCLC1) are located on chromosomes 1, 5, 9, 11, 13, 16 and 19, with two of the members, $b 1$ and $c 2$, both being on chromosome 16 (Fig. 1). The coding sequence (CDS) lengths of these CLCs are between 2178 and 2472 bases. With the exceptions of $G m C L C 1, c 1$, and $d 1$ (which are identical between the wild and cultivated soybeans), a few synonymous nucleotide substitutions were found in the other CLC members between G. $\max$ cultivar N23674 and G. soja accession. The only exception is $c 2$ where there is a 462 $\mathrm{T}>\mathrm{A}$ substitution from cultivar N23674 to accession BB52, which resulted in the corresponding D154E change (Additional file 1: Table S1).
Differential expressions of CLCs in G. max and G. soja under $\mathrm{NaCl}$ stress

Under normal growth conditions, all eight CLC homologs were expressed in roots, stems and leaves of 15-day-old seedlings of G. max cultivar N23674 and G. soja accession BB52. Generally, the relative expressions in the leaves of most of the CLC homologs, including GmCLC1 [21, 29, 30], b1, b2, d1, $d 2$ and $g$, were markedly higher than those in the roots and stems of both wild and cultivated soybeans. However, the relative expressions of $c 1$ and $c 2$ showed a different trend. Expression of both $c 1$ and $c 2$ was lower in leaf than in root and stem of N23674 (Fig. 2a). Expression of $c 1$ in BB52 showed no significant difference in leaf, stem and root. But expression of $c 2$ was significantly higher in stem compared to that in root and leaf (Fig. 2a). When the plants were treated with $150 \mathrm{mM} \mathrm{NaCl}, G m C L C 1, b 1$ and $b 2$ were initially up-regulated (for the first $2 \mathrm{~h}$ ) and were then down-regulated quickly in the leaves of both N23674 and BB52, whereas the expression of member $g$ in the leaves declined gradually with increasing salt treatment time in N23674 but fluctuated in the leaves of BB52 (Fig. 2b-e). The expressions of $G m C L C 1, b 1$ and $b 2$ were slightly up-regulated in the roots and stems of both wild and cultivated soybean seedlings under salt stress after $8 \mathrm{~h}$ (Fig. 2b-e). With respect to $d 1$ and $d 2$, their expressions decreased after the first $2 \mathrm{~h}$ in the roots and stems and after $8 \mathrm{~h}$ in the leaves, and then increased again with longer salt treatment time to about the same level as before the salt treatment (Fig. 2h-i). On the other hand, the expressions of $c 1$ and $c 2$ in the leaves peaked after $12 \mathrm{~h}$ of $\mathrm{NaCl}$ exposure and then dropped back to the level before salt treatment (Fig. 2f-g). More

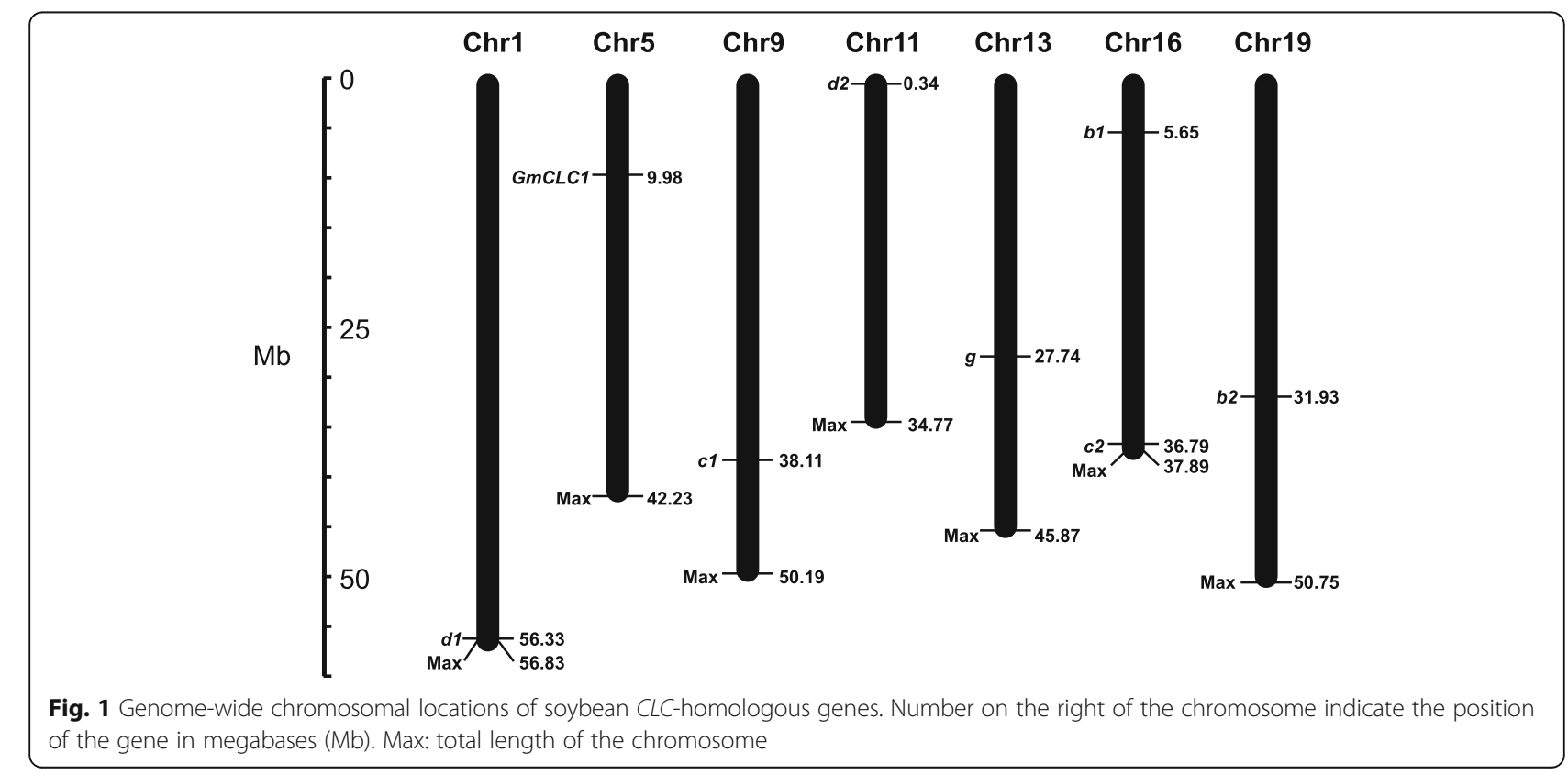


a
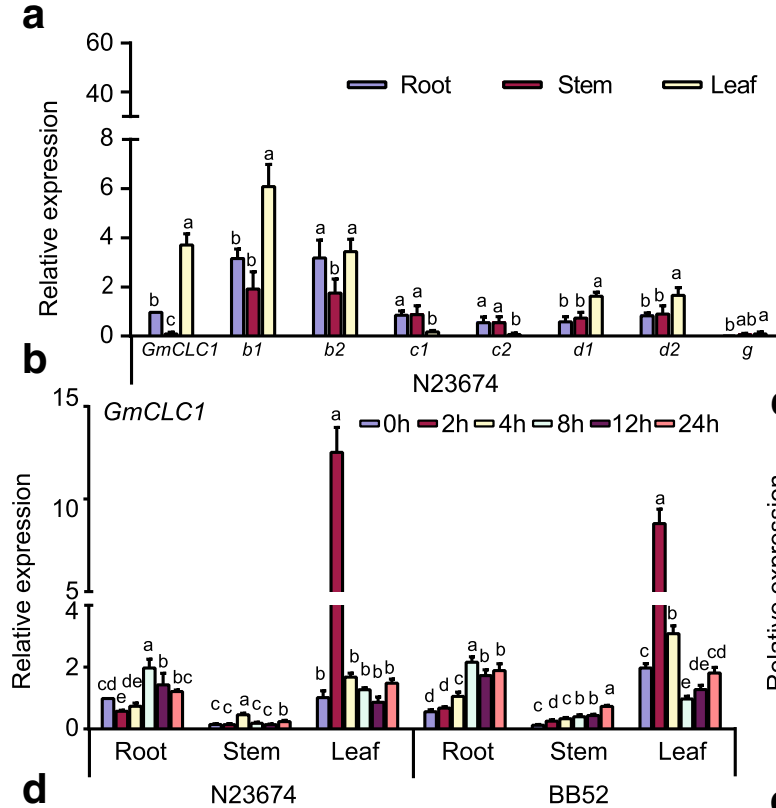

d

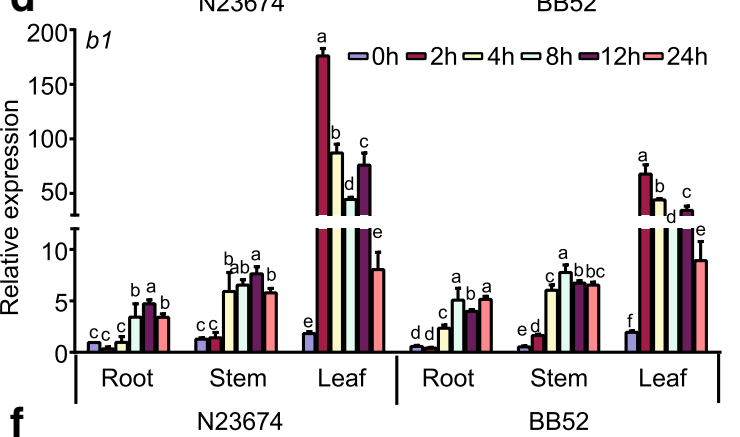

f

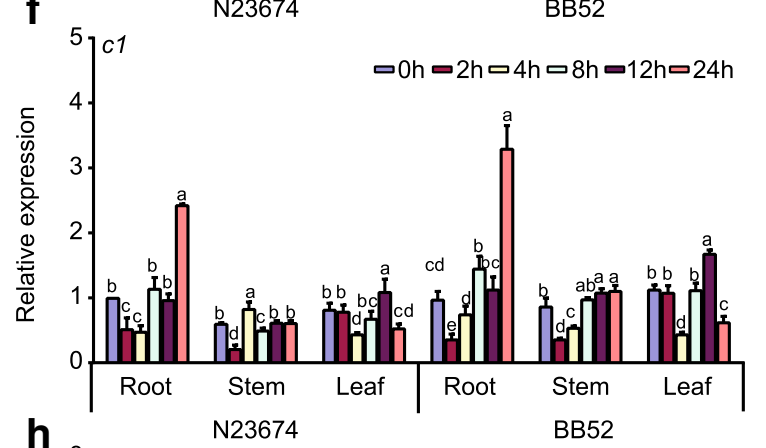

h

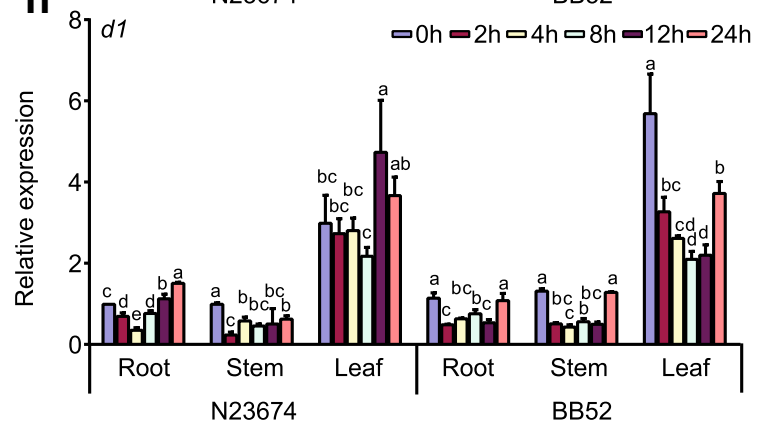

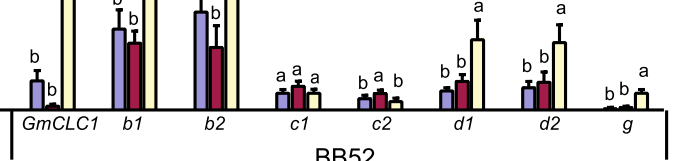

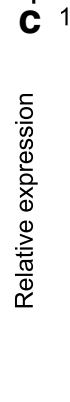

$\mathbf{e}_{2}$

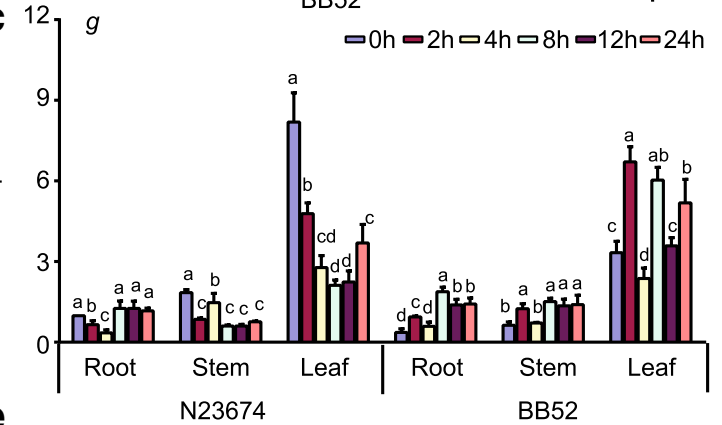

g
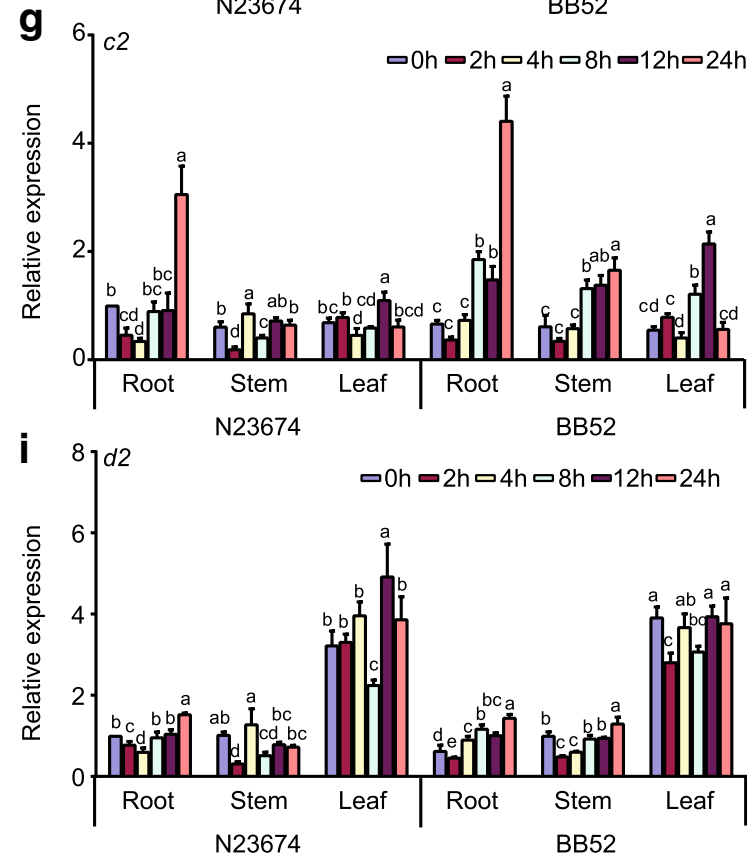

Fig. 2 (See legend on next page.) 
(See figure on previous page.)

Fig. 2 Relative expressions of CLC-homologous genes in G. max N23674 and G. soja BB52 15-day-old seedlings. a Under normal conditions. All expressions were normalized to the expression of GmCLC1 in root of N23674. Expression of GmCLC1 in root in N23674 was set as 1 for comparison. b-i Expression of different CLC-homologs under $150 \mathrm{mM} \mathrm{NaCl}$ stress for 0, 2, 4, 8, 12, and $24 \mathrm{~h} .9, b 1, b 2, C 1, C 2, d 1$ and $d 2$ are CLC homologs. The transcript levels have been normalized against those of GmEF1a2a. Expression of the gene in root of N23674 was set as 1 for comparison. The results were presented as mean \pm SD $(3 \leq n \leq 5)$. Letters indicate groups with statistically significant differences $(P \leq 0.05)$ using Duncan's test after one-way ANOVA

significantly, their expressions in the roots increased more than 2 -fold after $24 \mathrm{~h}$ of salt treatment, in both N23674 and BB52 (Fig. 2f-g). The distinctively different transcriptional responses of $c 1$ and $c 2$, in the different tissues under both normal and salt-stress conditions and in both wild and cultivated soybeans, from those of the other soybean $C L C$ members make them warrant further investigation. Between the two, $c 2$ is the only one with a difference in amino acid sequences between G. max cultivar N23674 and G. soja accession BB52 (Additional file 1: Table S1). Therefore, we decided to examine in greater detail what physiological (including electrophysiological) and molecular roles the version of $c 2$ found in G. soja BB52 (heretofore to be named $G s C L C-c 2$ ) might play in soybean $\mathrm{Cl}^{-} /$salt tolerance.

\section{Certain site-directed mutagenesis (SDM) mutants of GsCLC-c2 failed to complement the chloride channel- deficient yeast mutant $\Delta$ gef1 under $\mathrm{NaCl}, \mathrm{KCl}$, or $\mathrm{KNO}_{3}$ treatment}

All the yeast strains, including the WT (BY4741), Agef1 (a GEF1-deficient, salt-sensitive mutant), and $\Delta g e f 1$ transformed with $G s C L C-c 2$ or SDM mutants of GsCLC-c2 (S184P, E227V, E294G, C638F, A746T and I71V/C165Y), grew well on both YPD (yeast extract, peptone, dextrose) and YPG (yeast extract, peptone, galactose) media under favorable conditions. When cultured on YPG medium supplemented with $1 \mathrm{M} \mathrm{KCl}$, or $\mathrm{NaCl}$, the $\Delta g e f 1$ mutant was unable to grow, but this phenotype was rescued by transformation with wild type GsCLC-c2. However, mutants transformed with S184P, E227V, and E294G, with the key residues of the conserved domains I, II and III, respectively, of $G s C L C-c 2$ mutated, failed to complement the growth defect of yeast cells in the presence of high concentrations of chloride salts. This suggested that these mutants could not mediate $\mathrm{Cl}^{-}$homeostasis in yeast, and therefore these specific residues may be important for the anion transport activity of GsCLC-c2. The other GsCLC-c2 mutants, C638F, A746T, and I71V/C165Y, however, could complement the $\triangle g e f 1$ mutation, similar to the $\triangle g e f 1$ mutants transformed with the wild type $G s C L C-c 2$ (Fig. 3a). The $\mathrm{Cl}^{-}$contents of WT, $\triangle g e f 1 / G s C L C-c 2$ and $\triangle$ gef1/GsCLC-c2 mutants (C638F, A746T, and I71V/ $C 165 Y$ ) grown in $1 \mathrm{M} \mathrm{NaCl}$ were significantly higher than those of the $\Delta$ gefl mutants or $\Delta g e f$ mutants transformed with S184P, E227V, and E294G $(P<0.05)$, and the $\Delta g e f$ mutants transformed with $S 184 P$ or $E 227 V$ had similar
$\mathrm{Cl}^{-}$levels as the untransformed $\Delta g e f 1$ mutants (Fig. $3 \mathrm{~b}$ ). This indicates that GsCLC-c2 has a similar function to the yeast GEF1 in $\mathrm{Cl}^{-}$transport, and that the S184P and E227V substitutions completely, and the E294G substitution partially, negated the $\mathrm{Cl}^{-}$transport function of GsCLC-c2.

\section{GsCLC-c2 alleviates salt injury on transformed soybean} hairy root composite plants by regulating the contents of $\mathrm{Na}^{+}, \mathrm{K}^{+}, \mathrm{Cl}^{-}, \mathrm{NO}_{3}{ }^{-}$and ratios of $\mathrm{Cl}^{-} / \mathrm{NO}_{3}{ }^{-}$and $\mathrm{Na}^{+} / \mathrm{K}^{+}$

Using confocal microscopy, majority of GFP tagged GsCLC-c2 was found co-localized with the RFP tagged tonoplast marker protein $\delta$-TIP (Fig. 4) suggesting that GsCLC-c2 may serve similar functions as other tonoplast localized CLCs.

To confirm the function of GsCLC-c2, we adopted the soybean hairy root-composite plant system. Composite plants expressing $\mathrm{GmCLC1}$ were used for comparison. For each parameter, multiple comparisons were performed to compare the performance of all transgenic lines under control and treatment conditions using one-way ANOVA. Under favorable (control) conditions, the empty vector-transformed, GsCLC-c2-transformed and GmCLC1-transformed hairy root soybean (G. max cv. N23674) composite plants all grew well with no observable phenotypic difference in term of fresh weight, root vigor, leaf area, relative water content (RWC) in first trifoliate, and relative electrolyte leakage (REL) in root and leaf (Fig. 5). When subjected to $120 \mathrm{mM} \mathrm{NaCl}$ solution for $7 \mathrm{~d}$, all parameters were significantly affected compared to the control condition regardless of the transgene. The GsCLC-c2-transformed plants showed significantly better performance in fresh weight, root vigor, leaf area and RWC in the first trifoliate compared with the vector only control and the GmCLC1-transformed plants (Fig. 5b-e). Plant transformed with GsCLC-c2 also showed less REL suggesting that they were under less salt damage at cellular level in contrast to the vector only control and the GmCLC1-transformed plant (Fig. 5f-g).

To confirm the salt tolerance was brought about by the primary functions of $G s C L C-c 2$, we also investigated the ion content in the transgenic composite plants. For each parameter, multiple comparisons were made to compare the performance of all transgenic lines in each tissue under control and treatment conditions using one-way ANOVA. Under control conditions, there was no significant difference in $\mathrm{Cl}^{-}, \mathrm{Na}^{+}, \mathrm{Cl}^{-} / \mathrm{NO}_{3}{ }^{-}$and $\mathrm{Na}^{+} / \mathrm{K}^{+}$ratio 

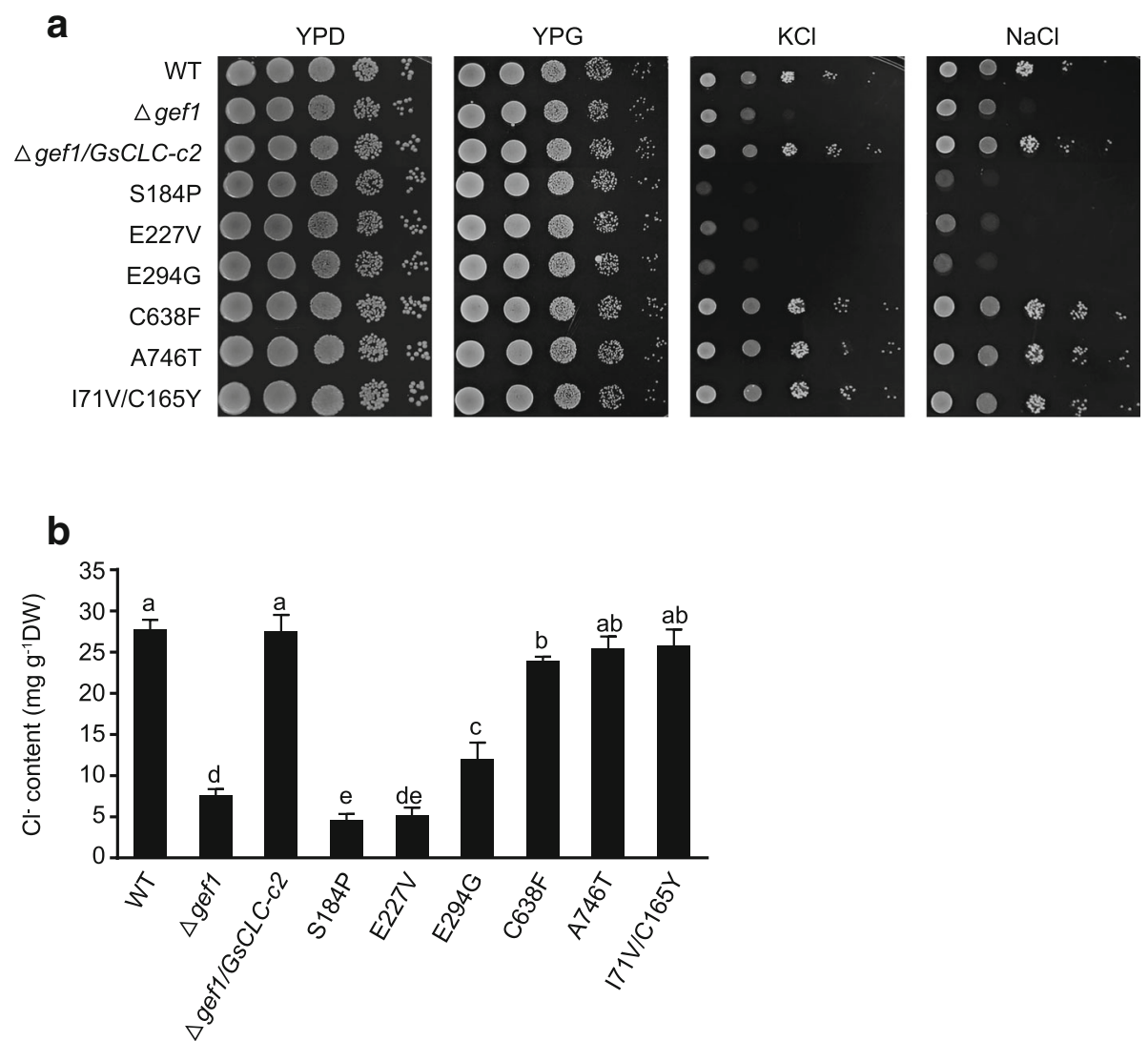

Fig. 3 Effects of expressing wild type or mutant GsCLC-C2 on salt-sensitive yeast mutant $\triangle$ gef1 under salt treatments. a Survival in YPD and YPG media, and YPG media supplemented with $1 \mathrm{M} \mathrm{KCl}$ or $1 \mathrm{M} \mathrm{NaCl}$. b Cl ${ }^{-}$contents in yeast cells under $1 \mathrm{M} \mathrm{NaCl}$ treatment. S184P, E227V, E294G, C638F, A746T and I71V/C165Y are mutants with specific amino acid substituted. YPD:1\% yeast extract/2\% peptone/2\% dextrose; YPG:1\% yeast extract $/ 2 \%$ peptone $/ 2 \%$ galactose. Each bar represents mean \pm SD of ion contents of three independent cultures of each strain. Letters indicate groups with statistically significant differences $(P \leq 0.05)$ using Duncan's test after one-way ANOVA

between the three constructs. Under the same conditions, composite plant of GsCLC-c2 showed significantly higher $\mathrm{NO}_{3}{ }^{-}$content in stem and $\mathrm{K}^{+}$content in root and leaf. Under salt stress, all lines showed elevation of $\mathrm{Cl}^{-}$and $\mathrm{Na}^{+}$contents but reduction in $\mathrm{NO}_{3}{ }^{-}$and $\mathrm{K}^{+}$contents.
Both CLCs expressing plants showed higher $\mathrm{Cl}^{-}$content (accompanying with a higher $\mathrm{Na}^{+}$content) in the root but a reduction of $\mathrm{Cl}^{-}$content (accompanying with a reduction of $\mathrm{Na}^{+}$content) in the aerial parts (Fig. 6a and d). With respect to $\mathrm{NO}_{3}{ }^{-}$, its level is higher in stem and leaf

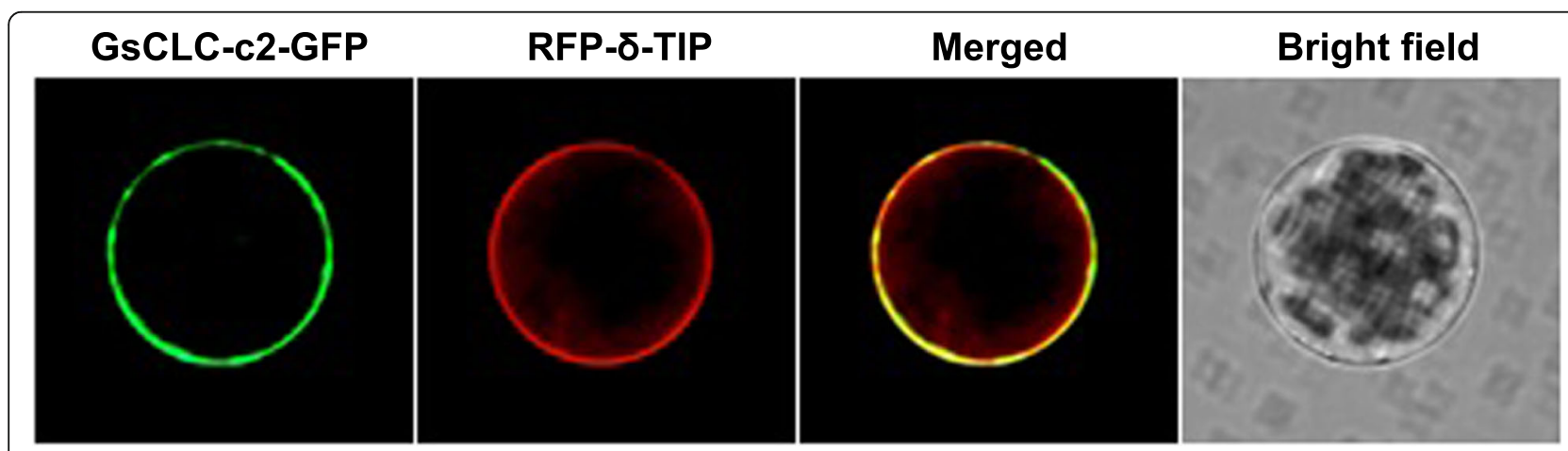

Fig. 4 Subcellular co-localization of GsCLC-c2-GFP and S-TIP-RFP recombinant proteins in leaf protoplasts of Arabidopsis seedlings. GsCLC-c2-GFP and $\delta$-TIP-RFP were expressed in Arabidopsis leaf protoplasts under the control of CaMV-35S promoter. $\delta$-TIP-RFP was used as the tonoplast marker 


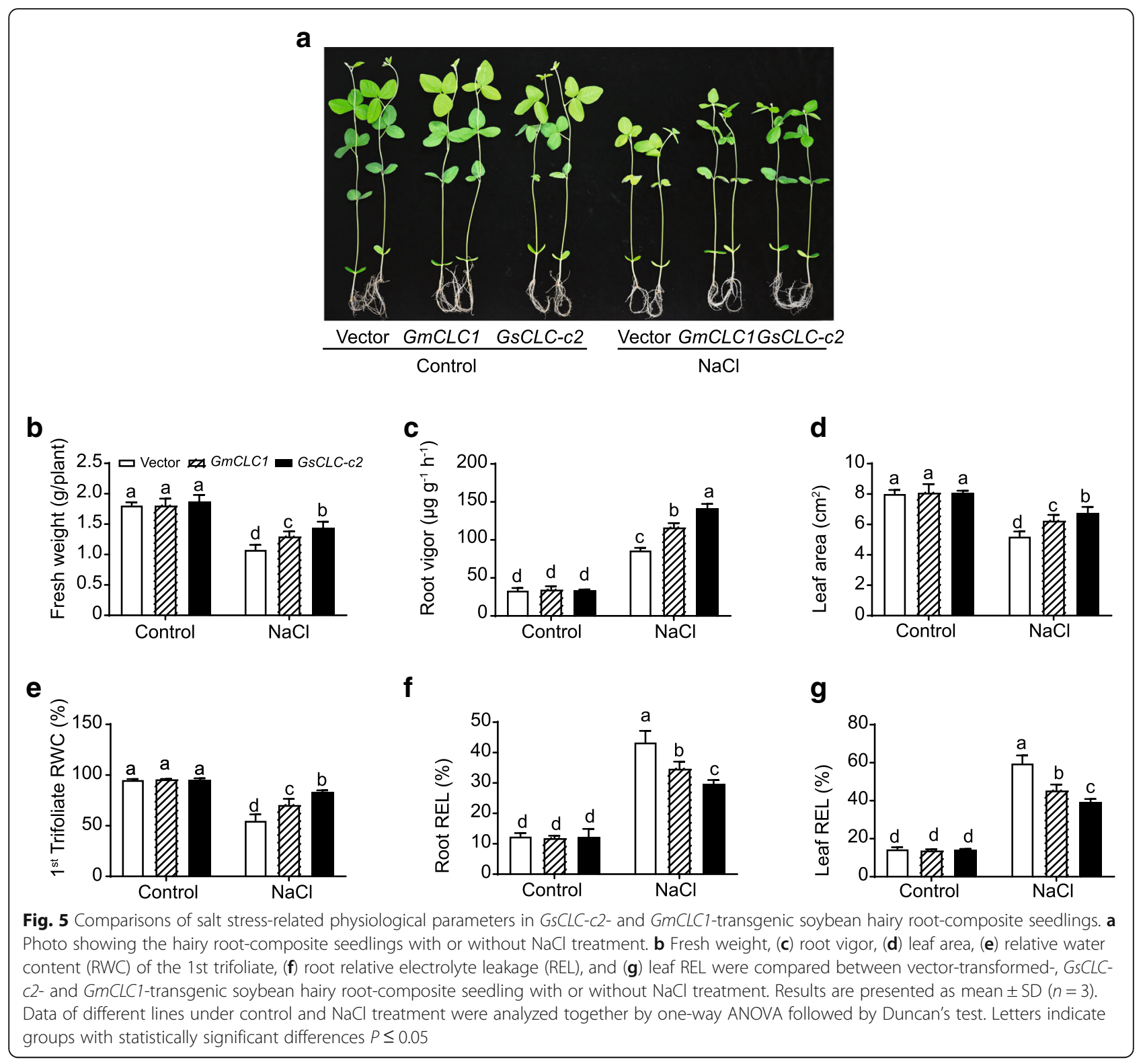

of composite plant ectopically expressing $G s C L C$-c 2 under salt stress conditions (Fig. 6b). Accordingly, ectopic expression of GsCLC-c2 maintained significantly lower $\mathrm{Cl}^{-} /$ $\mathrm{NO}_{3}{ }^{-}$and $\mathrm{Na}^{+} / \mathrm{K}^{+}$ratios in stem and leaf (Fig. 6c-f). Again, like the physiological parameters, GsCLC-c2 transgenic plants accumulated a significantly lower $\mathrm{Cl}^{-}$content in the aerial parts compared with the vector-transformed and $G m C L C 1$-transformed plant (Fig. 6a) suggested that GsCLC-c2, under salt stress, has stronger ion transportation activities over GmCLC1.

\section{Electrophysiological analyses of Xenopus laevis oocytes expressing GsCLC-c2}

In order to further verify the anion transport activities of GsCLC-c2 to see if it is a bona fide anion channel protein, two-electrode voltage clamp experiments were performed using Xenopus laevis oocytes injected with GsCLC-c2 cRNAs, and the electrophysiological track records for membrane steady-state current changes were conducted in vivo at $20 \mathrm{mV}$ intervals between $-100 \mathrm{mV}$ and $+100 \mathrm{mV}$. Oocytes microinjected with water $\left(\mathrm{H}_{2} \mathrm{O}\right)$ were used as the negative control to monitor the basal current. The results showed that, with the increase in voltage from $-100 \mathrm{mV}$ to +100 $\mathrm{mV}$, the current increased at a much higher rate in the GsCLC-c2-transformed oocytes than the water-injected controls, reflecting a significant increase in the rate of change in conductance across the cell membrane. The invert rectifying current signified the movement of anion into or cation out of the oocytes. When the anion channel inhibitor 5-nitro-2-(3-phenylpropylamino) benzoic acid (NPPB) was 


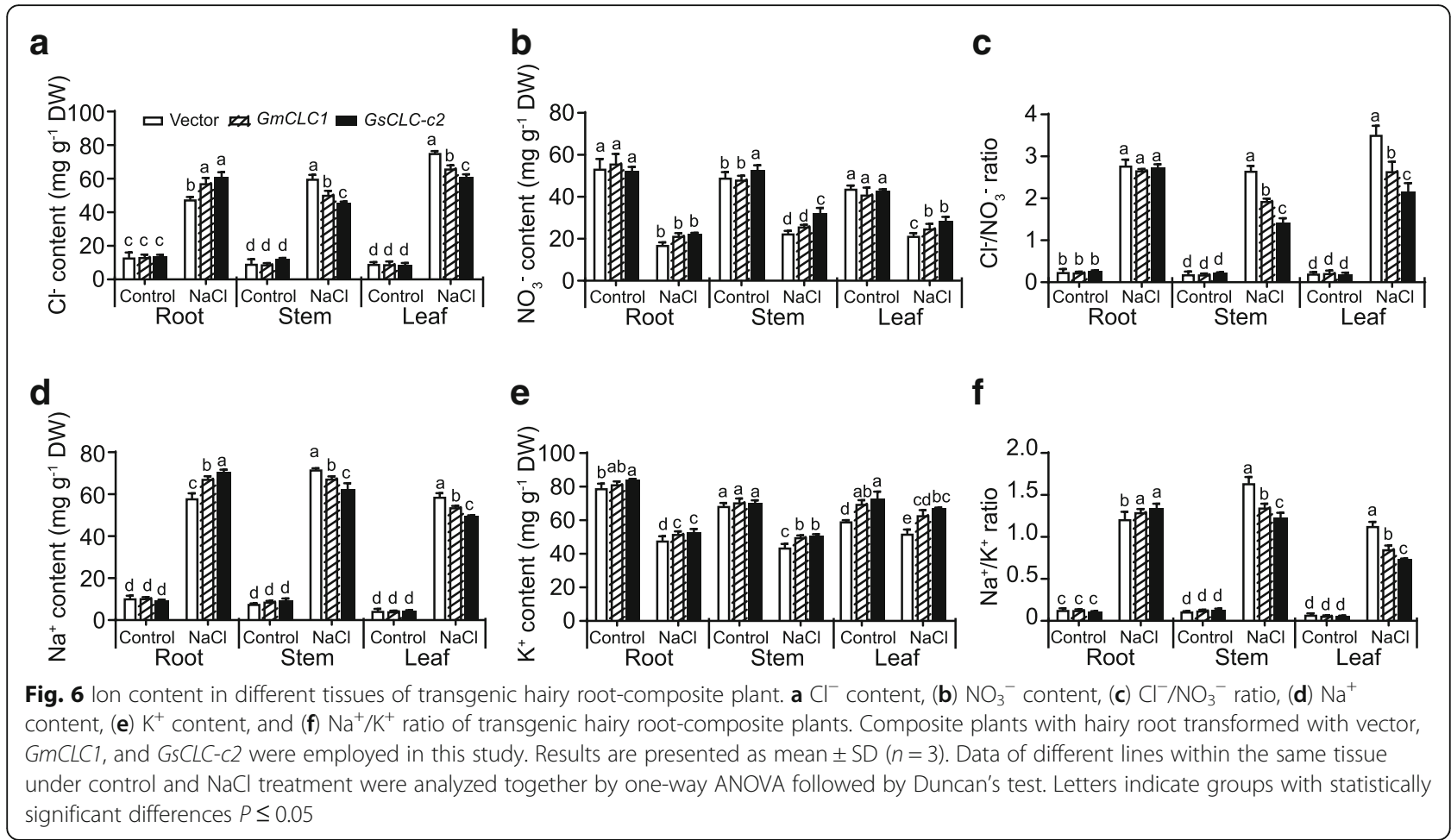

added to the extracellular bath solution, the voltagedependent change in current was not significantly different from the negative controls $\left(\mathrm{H}_{2} \mathrm{O}\right.$ and $\left.\mathrm{H}_{2} \mathrm{O}+\mathrm{NPPB}\right)$ (Fig. 7a). Therefore, this demonstrates that GsCLC-c2 possesses anion transport activity, and that anion is very likely $\mathrm{Cl}^{-}$, since NPPB is a well-known chloride channel blocker [31].

To confirm the voltage-dependent currents induced by GsCLC-c2 was mainly due to its $\mathrm{Cl}^{-}$transport activity, the currents across the membranes of GsCLC-c2-transformed oocytes, kept in $\mathrm{Cl}^{-}$solutions at different concentrations $(0,3,30,96 \mathrm{mM})$, were recorded. The rate of increase in membrane currents was in direct proportion to the increase in ambient $\mathrm{Cl}^{-}$concentration (Fig. 7b, Additional file 1: Figure S1), indicating that the anion transport activity of GsCLC-c2 was positively correlated with $\mathrm{Cl}^{-}$concentrations. However, this activity was independent of $\mathrm{pH}$ at the levels tested ( $\mathrm{pH} 5.5,7.5$ and 8.5) (Fig. 7c). This indicates that the $\mathrm{Cl}^{-}$transport activity of GsCLC-c2 may not be coupled with $\mathrm{H}^{+}$exchange. In addition, to investigate the affinity of GsCLC-c2 for different halide ions, GsCLC-c2-transformed oocytes were subjected to the standard bath solutions containing $\mathrm{Br}^{-}, \mathrm{I}^{-}$or $\mathrm{Cl}^{-}$at the same concentration. A voltage-dependent conductance response curve was obtained for all three ions, and the conductance responses to $\mathrm{Br}^{-}$and $\mathrm{I}^{-}$were about the same, and both were greater than that to $\mathrm{Cl}^{-}$(Fig. 7d).

Because of the discrepancy between the anion transport activity of GsCLC-c2 reported here and that of the previously reported $\mathrm{GmCLC1}$ with respect to $\mathrm{pH}$ dependence, we decided to directly compare the $\mathrm{Cl}^{-}$ transport activity between GsCLC-c2 and GmCLC1. Both $G s C L C-c 2$-transformed as well as $G m C L C 1$-transformed oocytes responded to the extracellular $\mathrm{Cl}^{-}$bath solutions with significantly higher rates of change in conductance with increasing voltage compared to water control. However, the increase in currents induced by GsCLC-c2 was significantly steeper than that by GmCLC1, which demonstrates that the $\mathrm{Cl}^{-}$transport activity of GsCLC-c2 is higher than that of GmCLC1 (Fig. 8a, Additional file 1: Figure S2). When GsCLC-c2-cRNA-transformed as well as GmCLC1-cRNA-transformed oocytes were exposed to either $\mathrm{Cl}^{-}$or $\mathrm{NO}_{3}{ }^{-}$bath solutions with the same anion concentrations, GmCLC1-cRNA-transformed oocytes did not show any significant difference between the current response curves to $\mathrm{Cl}^{-}$and to $\mathrm{NO}_{3}{ }^{-}$, but the response curve for $\mathrm{Cl}^{-}$was significantly steeper than that for $\mathrm{NO}_{3}{ }^{-}$in the GsCLC-c2-transformed oocytes. The signal also attenuated faster for $\mathrm{NO}_{3}{ }^{-}$than for $\mathrm{Cl}^{-}$with GsCLC-c2 (Fig. 8b). This indicates that, different from GmCLC1, GsCLC-c2 shows a slightly higher affinity for $\mathrm{Cl}^{-}$than for $\mathrm{NO}_{3}^{-}$.

\section{Discussion}

Investigations into $\mathrm{Cl}^{-}$toxicity have been relatively sparse compared to those on the effects of $\mathrm{Na}^{+}$on plants under salt stress $[11,14,20,32]$. One of the few examples is the discovery that the rootstocks from salt-tolerant species of citrus and grape played a critical role in enhancing the 
a $\stackrel{5}{\lessgtr}$

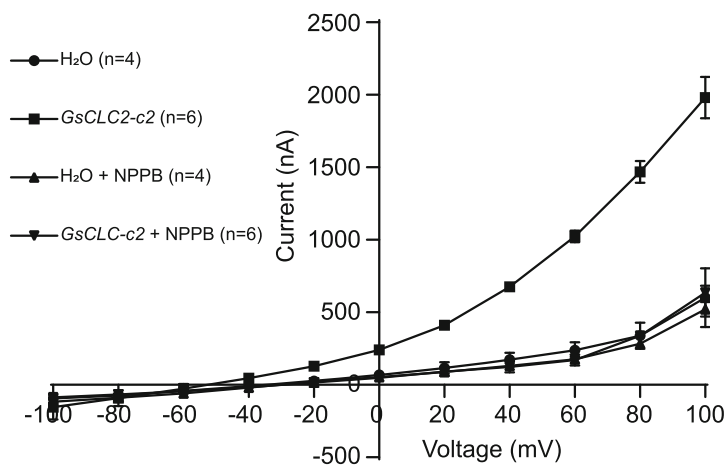

C
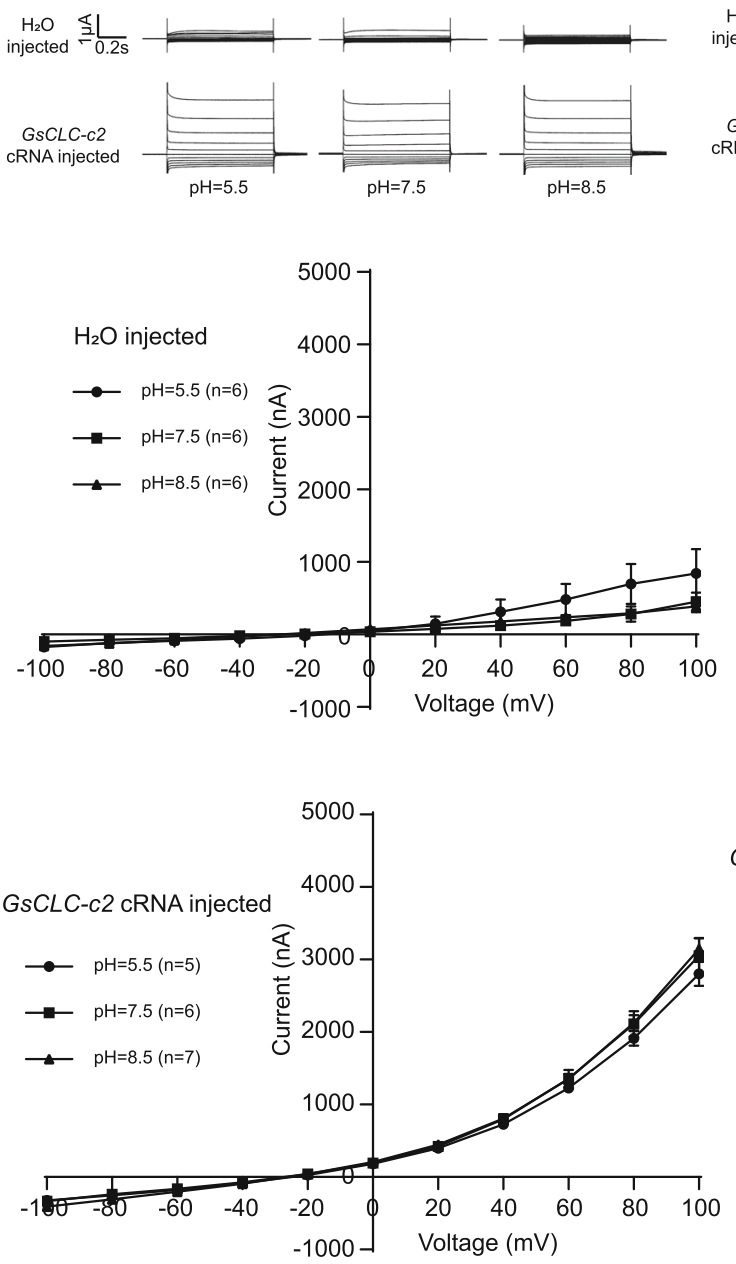

b
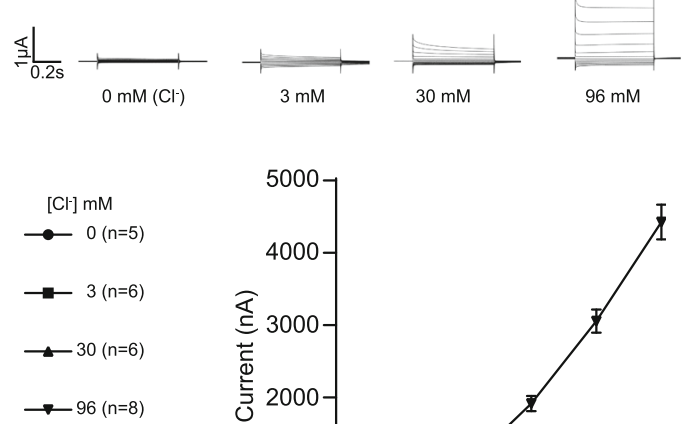
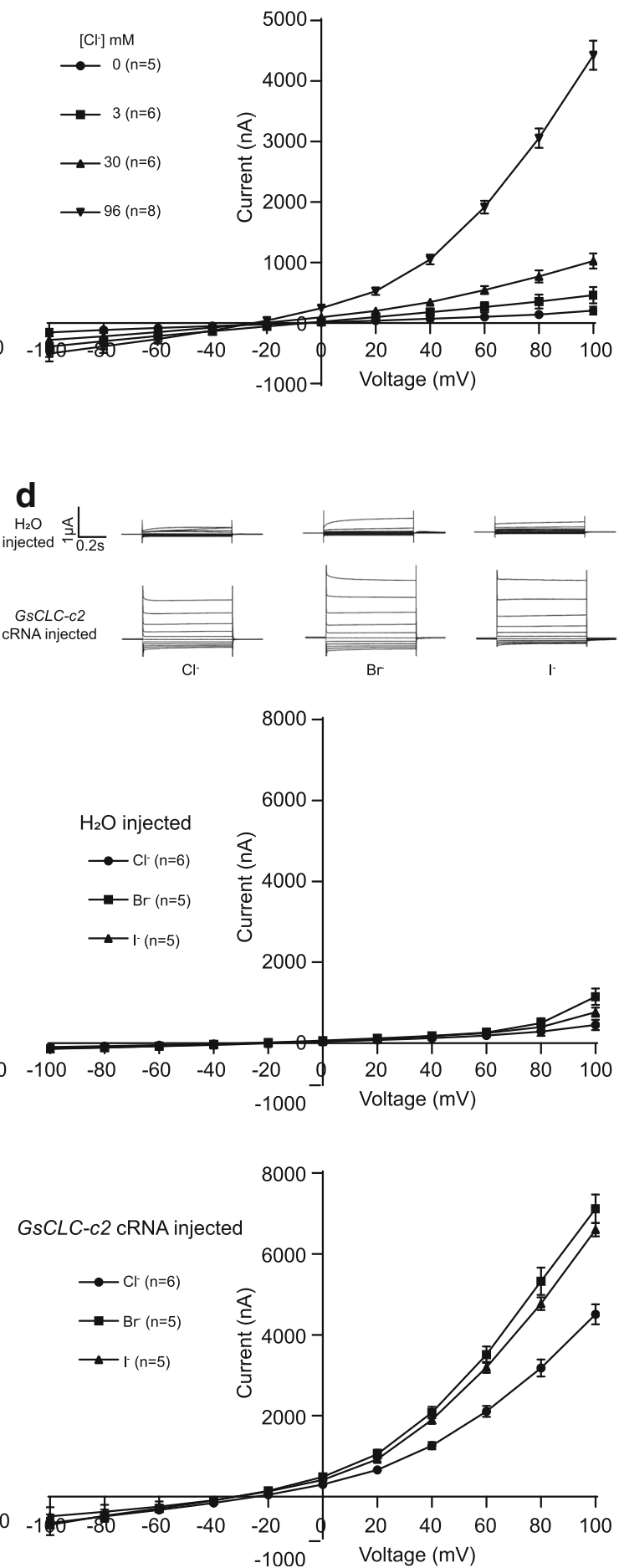

Fig. 7 (See legend on next page.) 
(See figure on previous page.)

Fig. 7 Voltage clamp analyses of GSCLC-c2 expressions in Xenopus laevis oocytes. a Effects of NPPB. Water- or GsCLC2-c2- cRNA injected oocytes were incubated in standard bath solution $(96 \mathrm{mM} \mathrm{NaCl})$ with or without the anion channel blocker NPPB. b Effects of $\mathrm{Cl}^{-}$concentrations. GsCLC2c2 cRNA injected oocytes were incubated in bath solution containing 0, 3, 30 or $96 \mathrm{mM} \mathrm{NaCl}$. c pH effect. GsCLC2-c2 cRNA injected oocytes were incubated in standard bath solution containing $96 \mathrm{mM} \mathrm{NaCl}$ at pH 5.5, 7.5, or 8.5. d Halide ion selectivity. Cells were kept in a bath solution containing $96 \mathrm{mM} \mathrm{NaCl}, \mathrm{NaBr}$ or Nal. Results are presented as mean $\pm \mathrm{SD}(n \geq 4)$

$\mathrm{Cl}^{-} /$salt tolerance of the "chloride-sensitive" or "chloridehating" seedlings [33-35]. Other studies have found that the key steps for alleviating $\mathrm{Cl}^{-}$toxicity involve the sequestering of $\mathrm{Cl}^{-}$in the root xylem parenchyma cells to limit its transport from the roots to the aerial parts, and the efflux of $\mathrm{Cl}^{-}$by the root stele cells or compartmentalization of $\mathrm{Cl}^{-}$in the vacuoles to reduce its availability in the roots $[11,36]$. CLCs can play important roles in these processes and contribute to $\mathrm{Cl}^{-}$ homeostasis and $\mathrm{Cl}^{-} /$salt tolerance of plants [24, 32, 37, 38]. In Arabidopsis, there are seven members in the CLC protein family but only AtCLCc and AtCLCg (with 62\% amino acid sequence identity to each other) have been shown to participate in $\mathrm{Cl}^{-}$homeostasis, stomatal movement and $\mathrm{Cl}^{-}$/salt tolerance [24, 32, 37, 39]. The ectopic expression of $C s C L C c$ from trifoliate orange (Citrus trifoliata) in Atclc-c mutant plants displayed improved seed germination, better growth and lower $\mathrm{Cl}^{-}$accumulation in the roots and shoots than the non-transgenic mutant seedlings under salt stress [38].

In this study, the other seven members besides $\mathrm{GmCLC1}$ $(b 1, b 2, c 1, c 2, d 1, d 2$ and $g$ ) of the soybean CLC gene family found in both G. $\max$ (cultivar N23674) and G. soja (accession BB52) have been successfully cloned for the first time and their sequences verified (Fig. 1, Additional file 1: Table S1). Specifically, $c 2$ is the only one that has an amino acid change between the cultivated (cultivar N23674) and the wild soybean (accession BB52): D154E, through a single nucleotide substitution (c.462 T > A) (Additional file 1: Table S1). At present, it is not clear whether this specific variation alone is responsible for the $\mathrm{Cl}^{-}$/salt tolerance differences between the cultivated and wild soybeans. However, based on the unique patterns of expressions of $c 1$ and $c 2$ in the roots, stems and leaves of N23674 and BB52 seedlings under both favorable and salt-stress conditions (Fig. 2), we postulate that GsCLC-c2 may be more responsible for soybean responses to $\mathrm{Cl}^{-} / \mathrm{NaCl}$ stress in root than other $C L C$ members. Similar to GmCLC1, GsCLC-c2 is also localized to the tonoplast (Fig. 4). Under $\mathrm{NaCl}$ stress, the salt damage to GsCLC-c2-overexpressing hairy roots composite soybean plants like the GmCLC1-overexpressing ones was clearly alleviated when compared to the empty vector-transformed plants (Fig. 5a). If we just look at the ionic effects of salt injury, this alleviation was correlated with the significant reduction in $\mathrm{Cl}^{-}$ contents of the stems and leaves of salt-stressed soybean plants, and indirectly related to the maintenance of $\mathrm{NO}_{3}{ }^{-}$accumulation in various parts of the plants $[9,21,22]$. These combined phenomena can effectively reduce the $\mathrm{Cl}^{-} / \mathrm{NO}_{3}{ }^{-}$ ratios in the stems and leaves of the plants (Fig. 6c). Based on the results from the $\Delta g e f 1$ yeast mutant assays (Fig. 3) and its localization on the tonoplast of Arabidopsis protoplasts (Fig. 4), we postulate that GsCLC-c2 probably affects this by increasing the sequestration of $\mathrm{Cl}^{-}$into the root cell vacuoles. Similarly, under salt stress, $\mathrm{K}^{+}$contents in the stems and leaves were increased, and $\mathrm{Na}^{+}$levels and $\mathrm{Na}^{+} / \mathrm{K}^{+}$ ratios were both reduced in the aerial parts while raised in the roots of $G s C L C$-c2-overexpressing hairy roots composite soybean plants, implying more $\mathrm{Na}^{+}$has been sequestered in the roots of these transgenic plants than in the controls (Fig. 6d-f). It is largely unknown how CLC regulates the $\mathrm{Na}^{+} / \mathrm{K}^{+}$ ratio. Yet, it has been suggested that $\mathrm{Cl}^{-}$and $\mathrm{Na}^{+}$transportation is somehow coupled [14]. Alteration of one would sometimes result in the alteration of the other [27, 40]. Furthermore, whether $G s C L C-c 2$ is directly involved in the $\mathrm{Cl}^{-}$accumulation or sequestration in the vacuoles of the roots of the transgenic composite soybean plants under salt stress, or whether it indirectly contributes to the restriction of $\mathrm{Cl}^{-}$transport from roots to shoots requires further investigations.

In Arabidopsis, whether the anion channel proteins, AtCLCa-d and AtCLCg, have a higher affinity for $\mathrm{NO}_{3}{ }^{-}$or $\mathrm{Cl}^{-}$is determined by the amino acid " $\mathrm{x}$ " in the highly conserved domain I - GxGIPE. If $\mathrm{x}$ is $\mathrm{P}$ (proline), $\mathrm{NO}_{3}{ }^{-}$ would be the preferred anion; if $\mathrm{x}$ is $\mathrm{S}$ (serine), $\mathrm{Cl}^{-}$would be preferred [24, 26]. GmCLC1, with $78 \%$ identity to AtClCa, is the first CLC reported in soybean and has a proline residue (P165) in the conserved domain I [23, 26]. Our previous study showed that GsCLC-c2 has a serine residue (S184) in the same conserved domain [23], and here we demonstrated that GmCLC1 did not show a preference between $\mathrm{Cl}^{-}$and $\mathrm{NO}_{3}{ }^{-}$whereas GsCLC-c2 had a slightly higher response to $\mathrm{Cl}^{-}$over $\mathrm{NO}_{3}{ }^{-}$(Fig. 8b).

Heterologous expression in special yeast mutants has been exploited by many researchers aiming to functionally characterize ion transporters from plant [21, 29, 30, 41, 42]. The GEF1-deficient yeast mutant ( $\Delta$ gef1)-based system was used to determine the efficacy of GmCLC1 in its ability to alleviate chloride/salt stress or its protective functions under $\mathrm{Cl}^{-}$stress [21]. In this study, the soybean $G s C L C-c 2$ gene was able to complement the salt-sensitive phenotype of the $\triangle$ gef1 mutant grown in YPG media containing $\mathrm{KCl}$ or $\mathrm{NaCl}$ (Fig. 3a). When GsCLC-c2 was mutated by one amino acid substitution (S184P, E227V, and E294G in the conserved domains I, II, and III, respectively), its ability to complement the gef1 mutation in yeast was very much abolished. The ability of the S184P-transformed yeast mutant to accumulate 
a
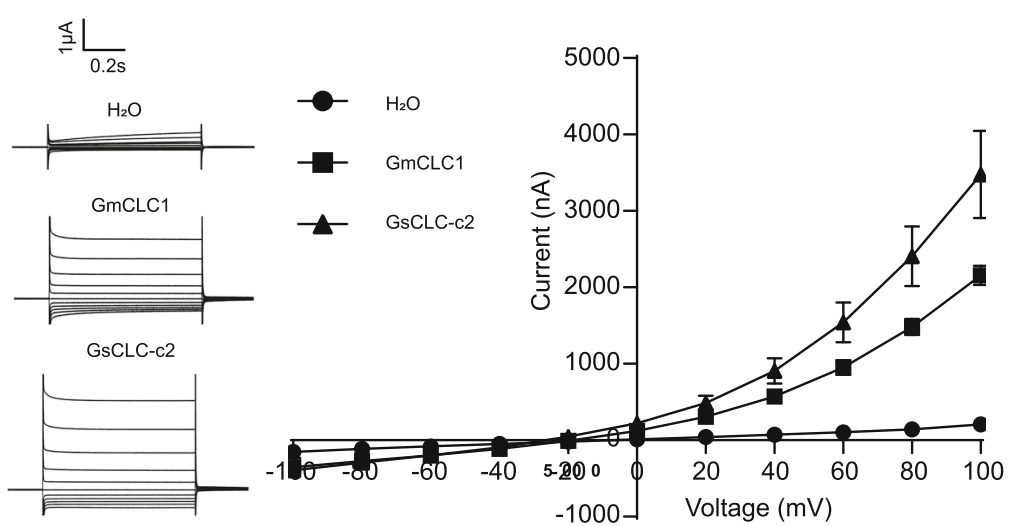

b
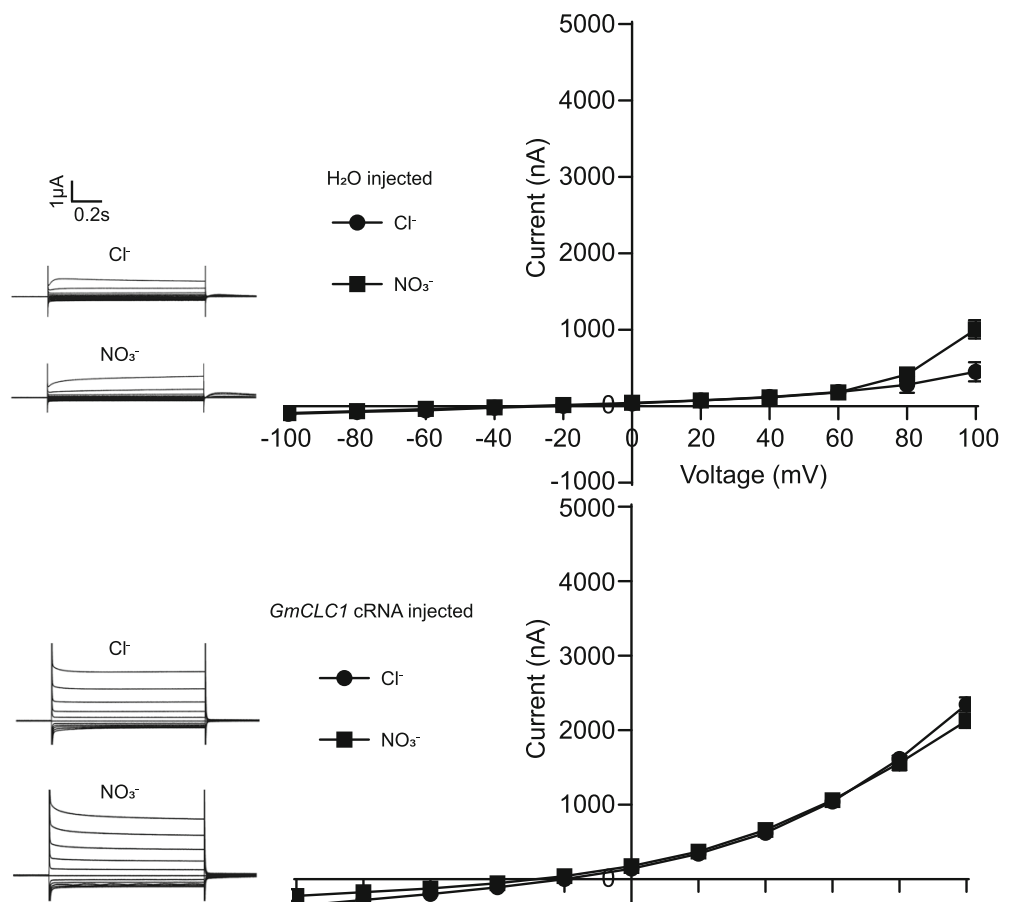

GmCLC1 cRNA inject
$\longrightarrow \mathrm{Cl}^{-}$
$-\mathrm{NO}_{3}^{-}$
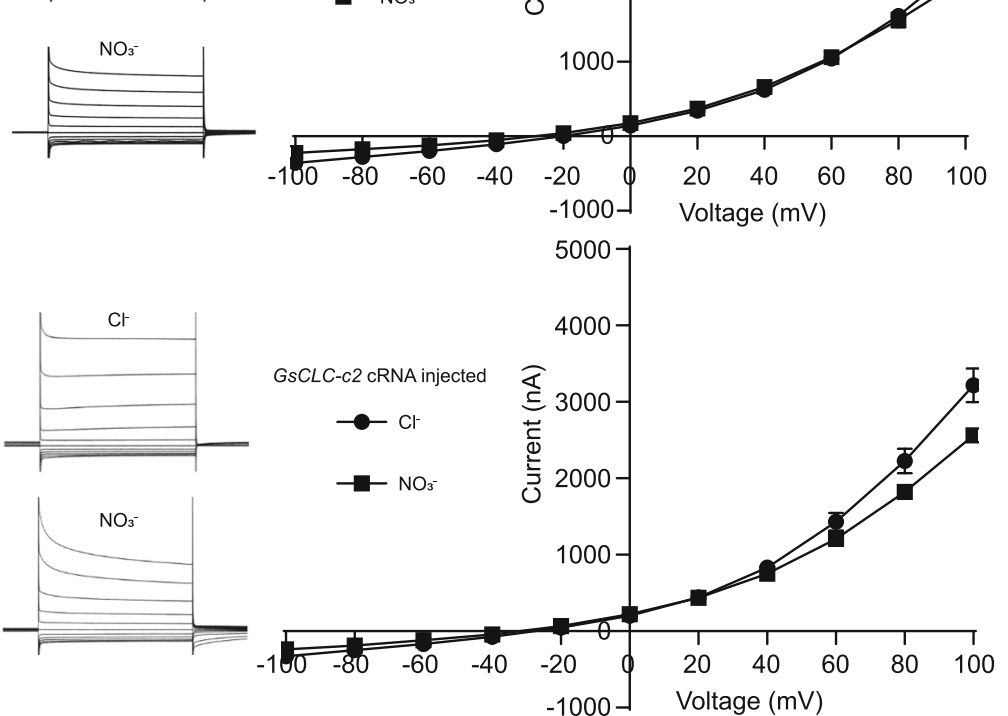

Fig. 8 (See legend on next page.) 
(See figure on previous page.)

Fig. 8 Electrophysiological comparisons of Xenopus laevis oocytes expressing GSCLC-C2 and GmCLC1. a lon transport activity in a bath solution containing $96 \mathrm{mM} \mathrm{NaCl}$. b Cl${ }^{-}$and $\mathrm{NO}_{3}{ }^{-}$selectivity in a bath solution containing $96 \mathrm{mM} \mathrm{NaCl}$ or and $96 \mathrm{mM} \mathrm{NaNO}_{3}$, respectively. Results are presented as mean \pm SD $(n \geq 5)$. Upper panel: oocytes were injected with water; middle panel: oocytes were injected with GmCLC1 CRNA; lower panel: oocytes were injected with GsCLC-c2 CRNA

$\mathrm{Cl}^{-}$in the cells was also drastically reduced (Fig. 3b), which could be the result of changing the $\mathrm{Cl}^{-}$or $\mathrm{NO}_{3}^{-}$specificity by the presence of either serine or proline in the determining position within the conserved domain I. However, the other mutations, such as C638F, A746T and I71V/C165Y within the non-conserved areas had no effect on the ability of GsCLC-c2 to complement the restrained growth of the $\Delta$ gefl mutant in media containing $\mathrm{KCl}, \mathrm{NaCl}$ (Fig. 3). The $\Delta$ gef1 mutant transformed with these mutated forms of GsCLC-c2 also accumulated comparable levels of $\mathrm{Cl}^{-}$to those transformed with the wild type GsCLC-c2 (Fig. 3b), indicating that these non-conserved domains may not play any part in the protein's function as an anion/chloride channel. This result also implied that introducing these amino acid substitutions has little effect on the function of this protein by affecting its conformation (Fig. 3).

The $X$. laevis oocyte, a heterologous expression system, has been successfully used to study various biological processes and ion channels [30, 43]. In this work, GsCLC-c2-expressing X. laevis oocytes displayed a significantly elevated voltage-dependent conductance when bathed in a solution containing $96 \mathrm{mM} \mathrm{NaCl}$, and this was negated by the inhibitory effect of the chloride channel blocker, NPPB (Fig. 7a). Furthermore, the conductance exhibited by the GsCLC-c2-expressing oocytes was elevated in proportion to increasing $\mathrm{Cl}^{-}$concentrations (Fig. 7b, Additional file 1: Figure S1), but, surprisingly, independent of $\mathrm{pH}$ (Fig. 7c). The latter indicates that the $\mathrm{Cl}^{-}$transport function of GsCLC-c2 does not involve $\mathrm{H}^{+}$exchange, and this is not consistent with the functions of AtCLCa, which can transport $\mathrm{Cl}^{-}$or $\mathrm{NO}_{3}{ }^{-}$ reversely coupled with $\mathrm{H}^{+}$transport, and its affinity for $\mathrm{NO}_{3}{ }^{-}$is stronger than for $\mathrm{Cl}^{-}[43,44]$. GsCLC-c2 is also different from GmCLC1, whose anion transport function showed pH dependence [30]. It appears that GsCLC-c2 is an anion channel and not a $\mathrm{H}^{+}$/anion cotransporter as deduced from our previous bioinformatics analyses [23]. Therefore, further studies of the functions of GsCLC-c2 are required.

\section{Conclusions}

$G s C L C-c 2$ is up-regulated in the roots of $\mathrm{NaCl}$-stressed wild soybean plants, and the encoded protein is more effective than GmCLC1 as a chloride channel, with higher permeability to $\mathrm{Cl}^{-}$and higher affinity for $\mathrm{Cl}^{-}$than $\mathrm{NO}_{3}{ }^{-}$ than $\mathrm{GmCLC1}$, and is responsive to halide ions in general. Its chloride transport function is $\mathrm{pH}$-independent, but dependent on the amino acid sequences in the conserved domains I, II and III. It is localized in the tonoplast and therefore likely contributes to enhanced $\mathrm{Cl}^{-} /$salt tolerance in plants by increasing the sequestration of excess $\mathrm{Cl}^{-}$in the vacuoles of root cells and thus preventing $\mathrm{Cl}^{-}$from being transported to the shoots where it can result in cellular damages.

\section{Methods}

Plant materials, bacteria and yeast strains, Xenopus laevis oocytes, and plasmids

Plant seeds, including Glycine $\max$ (L.) Merr. cultivar N23674 (salt-sensitive) were obtained from National Center for Soybean Improvement, Key Laboratory of Biology and Genetic Improvement of Soybean, Nanjing Agricultural University, Nanjing, China. Seeds of G. soja accession BB52 (salt-tolerant) were collected from the coastal area in Shandong province of P.R. China $[8,12]$. No special permissions were required to use this wild soybean accession. Wild-type (WT) Arabidopsis thaliana Columbia-0 glabrous1-1 (Col-0 $g l 1-1$, alias Col-5) was a gift from Dr. H.Z. Shi lab of Texas Tech University, USA. Escherichia coli DH5 $\alpha$, Agrobacterium rhizogenes strain $\mathrm{K} 599$, plant transient expression vectors pIIT166-GFP and PIIT166-RFP, binary vector for plant transformation pCAMBIA1300, yeast mutant $\Delta$ gef1 in BY4741 background and yeast expression plasmid pYES2, Xenopus laevis oocytes and plasmid pGEHME for the generation of cRNA were used in this study.

\section{Cloning of soybean CLC genes and vector construction for plant, bacterial and yeast transformation}

The seed germination and seedling cultivation of soybean were conducted as previously reported [21]. Total RNA was extracted from 15-day-old soybean seedlings using the TaKaRa MiniBEST Plant RNA Extraction Kit (TaKaRa, Dalian, China). The full-length coding sequence (CDS) of $C L C$ genes were amplified in PCR reactions containing $1 \times$ PCR buffer, $0.15 \mathrm{mM} \mathrm{MgCl}, 0.25 \mathrm{mM}$ dNTPs, $0.2 \mu \mathrm{M}$ of each primer, $0.25 \mathrm{U}$ KOD-Plus DNA polymerase (TOYOBO, Japan), and $2 \mu \mathrm{L}$ first-strand cDNA produced with PrimeScript $^{\text {ix }}$ II 1st Strand cDNA Synthesis Kit (TaKaRa, Dalian, China) according to the manufacturer's protocol. The PCR products were ligated to the pMD 19-T vector (TaKaRa, Dalian, China) and sequencing of the clones was done using the sequencing primer sites on the vector. Primer sequences are listed in Additional file 1: Table S2.

The CDS of GsCLC-c2 without the stop codon was cloned upstream of and in-frame with the CDS of green fluorescent protein (GFP) in the pJIT166-GFP plasmid 
to obtain the recombinant plasmid pJIT166-GsCLCc2-GFP. The tonoplast marker gene, $\delta$-TIP, for co-localization was cloned in-frame with the 3 '-terminus of red fluorescent protein (RFP) CDS in the pJIT166RFP plasmid to obtain pIIT166-RFP- $\delta$-TIP for Arabidopsis leaf protoplast transformation [39, 45]. The CDS of GsCLC-c2 was cloned into pCAMBIA1300 to obtain the pCAMBIA1300-GsCLC-c2, which was then transformed into A. rhizogenes $\mathrm{K} 599$ for plant transformation. To express $G s C L C-c 2$ in the yeast mutant $\triangle g e f 1$, the CDS was cloned into the yeast expression vector pYES2. To express $G s C L C-c 2$ and $G m C L C 1$ in X. laevis oocytes, their CDS were cloned into pGEHME. Primers used for amplifying the above genes are shown in Additional file 1: Table S2. pCAMBIA1300-GmCLC1 was constructed as our previous work [21].

\section{Chromosomal location determination}

In order to pinpoint the distribution of GmCLCs family members throughout the soybean genome, we used each member as a query against the soybean genome on the SoyBase Wm82 Genome Browser (https://www.soybase. org/gb2/gbrowse/gmax2.0/) to determine the location of the transcription initiation site of each gene. The MapInspect software (version 1.0) was used to draw the locations of $G m C L C$ genes on each chromosome.

\section{qRT-PCR assays}

The roots, stems, and leaves were sampled from 15-day-old N23674 and BB52 plants treated with $150 \mathrm{mM} \mathrm{NaCl}$ for 0,2 , $4,8,12$, and $24 \mathrm{~h}$, respectively, and were frozen in liquid $\mathrm{N}_{2}$ for RNA extraction. Total RNAs were isolated using MiniBEST Plant RNA Extraction Kit (TaKaRa, Dalian, China) and then used for the 1st strand cDNA synthesis following the instructions of PrimeScript RT reagent Kit with gDNA Eraser (TaKaRa). A soybean elongation factor 1-alpha-like gene, EF1 12a (XM_003524541.1) [46], was used as an internal reference. qRT-PCR reactions were performed in 96-well plates using the StepOnePlus Real-Time PCR System (ThermoFisher Scientific China, Inc., Shanghai) with SYBR ${ }^{\circ}$ Premix Ex Taq ${ }^{\text {Tm }}$ II (TaKaRa) according to manufacturer's protocols in a $10-\mu \mathrm{L}$ reaction. Data were analyzed by StepOnePlus Software v2.1 (Thermo Fisher Scientific China, Inc., Shanghai). The relative expression of each gene was normalized against the internal reference gene, and calculated according to the $2^{-\triangle \Delta C T}$ method [47]. Primers used in the qRT-PCR are presented in Additional file 1: Table S2.

\section{Subcellular co-localization assays of GsCLC-c2}

The seed germination and seedling cultivation of Arabidopsis were conducted as previously reported [21]. Arabidopsis protoplasts were isolated from the leaves of 25-day-old plants as previously reported [48]. Two fusion constructs GsCLC-c2-GFP and tonoplast specific marker RFP- $\boldsymbol{\delta}$-TIP [39] were co-transformed into the protoplast by the PEG4000-mediated method [49]. After incubation of the transformed Arabidopsis protoplasts for $18-24 \mathrm{~h}$ at room temperature, GFP and RFP signals were detected by confocal fluorescence microscopy (PerkinElmer UltraVIEW VoX).

\section{Site-directed mutagenesis (SDM)-mediated complementation tests of GsCLC-c2 in yeast mutant}

To investigate the $\mathrm{Cl}^{-}$transport functions of GsCLC-c2, site-directed mutagenesis of GsCLC-c2 was carried out. The strategies for the SDM of GsCLC-c2 are shown in Additional file 1: Table S3, and the mutations were performed with the Muta-direct ${ }^{\mathrm{tm}}$ site-directed mutagenesis Kit (SBS Genetech, Shanghai, China) using the pYES2-GsCLC-c2 construct according to manufacturer's protocol. The desired constructs confirmed with sequencing were transformed into the salt-sensitive yeast mutant $\Delta g e f 1$ as described previously [50]. The yeast cultures in 10-fold dilution series beginning at $\mathrm{OD}_{600} \approx 0.5$ were plated on YPD medium ( $1 \%$ yeast extract $/ 2 \%$ peptone $/ 2 \%$ dextrose), YPG medium ( $1 \%$ yeast extract $/ 2 \%$ peptone $/ 2 \%$ galactose), with or without $1 \mathrm{M} \mathrm{NaCl}$, or $1 \mathrm{M} \mathrm{KCl}$ supplement. The plates were photographed 2 4. days after incubation at $30^{\circ} \mathrm{C}$. $\mathrm{Cl}^{-}$contents of WT (S. cerevisiae BY4741), $\Delta g e f 1$ mutant, $\triangle g e f 1 / G s C L C-c 2$, or $\Delta g e f 1 /$ GsCLC-c2 mutants were determined with cultures grown in liquid YPG medium with $1 \mathrm{M} \mathrm{NaCl}$. Cells were harvested at OD600 $\approx 0.2$ by filtration, and their $\mathrm{Cl}^{-}$content was determined [51].

\section{Salt tolerance assays of GsCLC-c2 overexpressing hairy root composite soybean plants}

Hairy root transformation was performed as described in our previous work [21]. Soybean seedlings were transformed with pCAMBIA1300 (Vector), pCAMBIA1300-GsCLC-c2 or pCAMBIA1300-GmCLC1 using A. rhizogenes strain K599. Ten-day after K599 infection, seedlings with similar length of hairy roots were transferred to $1 / 2$ X Hoagland solution with or without 120 $\mathrm{mM} \mathrm{NaCl}$. Solution was replaced every 3 days. Roots, stems and leaves were harvested 7-day after transfer for $\mathrm{Na}^{+}, \mathrm{K}^{+}, \mathrm{Cl}^{-}$and $\mathrm{NO}_{3}{ }^{-}$content measurement $[51,52]$. Photos of plants were taken right before sample harvest.

\section{Xenopus laevis oocyte transformation with GsCLC-c2 by microinjection and electrophysiology}

Ambion mMESSAGE mMACHINE ${ }^{\mathrm{m}} \mathrm{T}$ T7 Transcription Kit (AM1344, Life Technologies, California, United States) was used to synthesize capped cRNAs from linearized pGEHME-GsCLC-c2 and pGEHME-GmCLC1. Harvesting and handling of $\mathrm{X}$. laevis oocytes were done as previously described [30]. Oocytes were injected with either $50 \mathrm{~nL}$ of $\mathrm{H}_{2} \mathrm{O}$ or $50 \mathrm{~nL}$ of $1 \mathrm{ng} \mathrm{L}^{-1}$ cRNA. The injected oocytes were incubated in the standard bath solution $(96 \mathrm{mM} \mathrm{NaCl}, 2 \mathrm{mM}$ 
potassium gluconate, $5 \mathrm{mM}$ calcium D-gluconate, $1.2 \mathrm{mM}$ $\mathrm{MgSO}_{4}, 5 \mathrm{mM}$ HEPES, pH 7.5) at $16 \sim 18{ }^{\circ} \mathrm{C}$ [43] before two-electrode voltage clamping. Data acquisition and analysis were done using the oocyte clamp recording interface (Warner Instrument OC-725C, Hamden, CT, USA) and pClamp9 software (Molecular Devices, San Jose, CA, USA) [30]. To verify whether GsCLC-c2 is a bona fide $\mathrm{Cl}^{-}$transporter, oocytes expressing the transporter were challenged with bath solution with different concentration of $\mathrm{Cl}^{-}$and $10 \mu \mathrm{M}$ NPPB (5-nitro-2-[3-phenylpropylamino] benzoic acid, an anion channel inhibitor) [31]. In order to determine the effect of extracellular $\mathrm{pH}$ on the transporter function in the range of 5.5 to 8.5 , the bath solution was buffered with 5 $\mathrm{mM}$ MES for $\mathrm{pH} 5.5$, and with $5 \mathrm{mM}$ Tris for $\mathrm{pH}$ 8.5. In ion substitution experiments, $96 \mathrm{mM} \mathrm{NaCl}$ was substituted with equal concentrations of $\mathrm{NaI}, \mathrm{NaBr}$ or $\mathrm{NaNO}_{3}$. $\mathrm{Ag} / \mathrm{AgCl}$ electrodes and $3 \mathrm{M} \mathrm{KCl}$ agar bridges were used as reference and bath electrodes, respectively [30].

\section{Statistical analyses}

All data were analyzed and presented as the means \pm SD for each treatment $(n=3$; except for electrophysiology where $n=4 \sim 9$ ) using SPSS software (ver. 20.0). The data were subjected to the one-way analysis of variance (ANOVA), and pairwise comparisons were performed using Duncan's test at $P \leq 0.05$. For physiological data, data of different transgenic lines under control and $\mathrm{NaCl}$ treatment conditions were compared. For ion content, data of different transgenic lines among the same tissue under control and $\mathrm{NaCl}$ treatment conditions were compared.

\section{Additional file}

Additional file 1: Figure S1. Pearson correlation of membrane currents of Xenopus oocytes injected expressing GsCLC-C2. Figure S2. Comparison of chloride transporting activity of GmCLC1 and GsCLC-c2. Table S1.

Summary of soybean CLC-homologous genes information in G. max (Cultivar N23674) and G. soja (accession BB52). Table S2. Primers for soybean CLC genes analyses. Table S3. Information for site-directed mutagenesis of GSCLC-c2 (DOCX $140 \mathrm{~kb})$

\section{Abbreviations}

ANOVA: Analysis of variance; CDS: Coding sequence; CLC: Chloride channel; Col-0 gl1-1: Arabidopsis thaliana Columbia-0 glabrous 1-1; GFP: Green fluorescent protein; NPPB: 5-nitro-2-(3-phenylpropylamino) benzoic acid; PSII: Photosystem II; REL: Relative electrolyte leakage; RFP: Red fluorescent protein; RWC: Relative water content; SDM: Site-directed mutagenesis; WT: Wild-type; YPD: Yeast extract, peptone, dextrose; YPG: Yeast extract, peptone galactose

\section{Acknowledgements}

We thank Ms. Jee Yan Chu for copy-editing the manuscript.

\section{Funding}

This work was supported by grants from the National Natural Science Foundation of China (31671604, U1603111) awarded to BJY, and the Hong Kong Research Grants Council Area of Excellence Scheme (AoE/M-403/16), CUHK VC Discretionary Fund VCF2014004, and the Lo Kwee-Seong
Biomedical Research Fund awarded to H-ML. Funding body had no role in the design of the study and collection, analysis, interpretation of data and in writing the manuscript.

\section{Availability of data and materials}

The datasets used and during the current study available from the corresponding author on reasonable request.

\section{Authors' contributions}

PW, BC, LS, YC, SW, and FL conducted the experiments, collected and analyzed all data. BY and H-ML designed the experiments. BY, PW, CC, M-WL, and $\mathrm{H}-\mathrm{ML}$ interpreted the data and wrote the manuscript. All authors read and approved the final version of the manuscript.

\section{Ethics approval and consent to participate}

Not applicable.

Consent for publication

Not applicable.

\section{Competing interests}

The authors declare that they have no competing interests.

\section{Publisher's Note}

Springer Nature remains neutral with regard to jurisdictional claims in published maps and institutional affiliations.

\section{Author details}

${ }^{1}$ Laboratory of Plant Stress Biology, College of Life Sciences, Nanjing Agricultural University, Nanjing, China. ${ }^{2}$ State Key Laboratory of Crop Genetics and Germplasm Enhancement, College of Life Sciences, Nanjing Agricultural University, Nanjing 210095, China. ${ }^{3}$ Center for Soybean Research of the State Key Laboratory of Agrobiotechnology and School of Life Sciences, The Chinese University of Hong Kong, Shatin, Hong Kong, China.

Received: 19 October 2018 Accepted: 19 March 2019

Published online: 01 April 2019

\section{References}

1. Deinlein U, Stephan AB, Horie T, Luo W, Xu G, Schroeder Jl. Plant salttolerance mechanisms. Trends Plant Sci. 2014;19(6):371-9.

2. Ondrasek $G$, Rengel Z, Veres S: Soil salinisation and salt stress in crop production. In: Abiotic stress in plants - mechanisms and adaptations. Edited by Shanker A. Rijeka, Croatia InTech; 2011: 171-190.

3. Roy SJ, Negrao S, Tester M. Salt resistant crop plants. Curr Opin Biotech. 2014;26:115-24

4. Genc Y, Oldach K, Taylor J, Lyons GH. Uncoupling of sodium and chloride to assist breeding for salinity tolerance in crops. New Phytol. 2016;210(1):145-56.

5. Ismail AM, Horie T. Genomics, physiology, and molecular breeding approaches for improving salt tolerance. Annu Rev Plant Biol. 2017;68:405-34.

6. Munns R, Tester M. Mechanisms of salinity tolerance. Annu Rev Plant Biol. 2008:59:651-81.

7. Hasegawa PM. Sodium $\left(\mathrm{Na}^{+}\right)$homeostasis and salt tolerance of plants. Environ Exp Bot. 2013;92:19-31

8. Zhang XK, Zhou QH, Cao JH, Yu BJ. Differential $\mathrm{Cl}^{-} /$salt tolerance and $\mathrm{NaCl}$ induced alternations of tissue and cellular ion fluxes in Glycine max, Glycine soja and their hybrid seedlings. J Agron Crop Sci. 2011;197(5):329-39.

9. Guo JS, Zhou Q, Li XJ, Yu BJ, Luo QY. Enhancing $\mathrm{NO}_{3}{ }^{-}$supply confers $\mathrm{NaCl}$ tolerance by adjusting $\mathrm{Cl}^{-}$uptake and transport in G. max \& G. soja. J Soil Sci Plant Nut. 2017;17(1):194-204

10. Henderson SW, Baumann U, Blackmore DH, Walker AR, Walker RR, Gilliham M. Shoot chloride exclusion and salt tolerance in grapevine is associated with differential ion transporter expression in roots. BMC Plant Biol. 2014;14:273.

11. Li B, Qiu J, Jayakannan M, Xu B, Li Y, Mayo GM, Tester M, Gilliham M, Roy SJ. AtNPF2.5 modulates chloride $\left(\mathrm{Cl}^{-}\right)$efflux from roots of Arabidopsis thaliana. Front Plant Sci. 2017;7. https://doi.org/10.3389/fpls.2016.02013.

12. Luo QY, Yu BJ, Liu YL. Differential sensitivity to chloride and sodium ions in seedlings of Glycine max and G. soja under NaCl stress. J Plant Physiol. 2005; 162(9):1003-12. 
13. Qu YN, Zhou Q, Yu BJ. Effects of $\mathrm{Zn}^{2+}$ and niflumic acid on photosynthesis in Glycine soja and Glycine max seedlings under $\mathrm{NaCl}$ stress. Environ Exp Bot. 2009;65(2-3):304-9.

14. Teakle NL, Tyerman SD. Mechanisms of $\mathrm{Cl}^{-}$transport contributing to salt tolerance. Plant Cell Environ. 2010;33(4):566-89.

15. Wege S, Gilliham M, Henderson SW. Chloride: not simply a 'cheap osmoticum' but a beneficial plant macronutrient. J Exp Bot. 2017;68(12):3057-69.

16. Franco-Navarro JD, Brumos J, Rosales MA, Cubero-Font $P$, Talon M, Colmenero-Flores JM. Chloride regulates leaf cell size and water relations in tobacco plants. J Exp Bot. 2016;67(3):873-91.

17. Chen CZ, LV XF, Li JY, Yi HY, Gong JM. Arabidopsis NRT1.5 is another essential component in the regulation of nitrate reallocation and stress tolerance. Plant Physiol. 2012;159(4):1582-90

18. O'Brien JA, Vega A, Bouguyon E, Krouk G, Gojon A, Coruzzi G, Gutierrez RA. Nitrate transport, sensing, and responses in plants. Mol Plant. 2016;9(6):837-56.

19. Cubero-Font P, Maierhofer T, Jaslan J, Rosales MA, Espartero J, Diaz-Rueda P, Muller HM, Hurter AL, AL-Rasheid KAS, Marten I, et al. Silent S-type anion channel subunit SLAH1 gates SLAH3 open for chloride root-to-shoot translocation. Curr Biol. 2016;26(16):2213-20.

20. Qiu JE, Henderson SW, Tester M, Roy SJ, Gilliham M. SLAH1, a homologue of the slow type anion channel SLAC1, modulates shoot $\mathrm{Cl}^{-}$accumulation and salt tolerance in Arabidopsis thaliana. J Exp Bot. 2016;67(15):4495-505.

21. Wei PP, Wang LC, Liu AL, Yu BJ, Lam HM. GmCLC1 confers enhanced salt tolerance through regulating chloride accumulation in soybean. Front Plant Sci. 2016;7. https://doi.org/10.3389/fpls.2016.01082.

22. Yu BJ, Liu Z, Wei PP. Research progresses on whole genome discovery and function analysis of CLC homologous genes in plants based on salt stress. Journal of Nanjing Agricultural University. 2017;40(2):187-94.

23. Li W, Wang LC, Cao JH, Yu BJ. Bioinformatics analysis of CLC homologous genes family in soybean genome. Journal of Nanjing Agricultural University. 2014;37(3):35-43.

24. Barbier-Brygoo H, De Angeli A, Filleur S, Frachisse JM, Gambale F, Thomine S, Wege S. Anion channels/transporters in plants: from molecular bases to regulatory networks. Annu Rev Plant Biol. 2011;62:25-51.

25. Wege S, Jossier M, Filleur S, Thomine S, Barbier-Brygoo H, Gambale F, De Angeli A. The proline 160 in the selectivity filter of the Arabidopsis $\mathrm{NO}_{3}{ }^{-} / \mathrm{H}^{+}$exchanger AtCLCa is essential for nitrate accumulation in planta. Plant J. 2010;63(5):861-9.

26. Zifarelli G, Pusch M. CLC transport proteins in plants. FEBS Lett. 2010;584(10):2122-7.

27. Lam HM, Xu X, Liu X, Chen WB, Yang GH, Wong FL, Li MW, He WM, Qin N, Wang $B$, et al. Resequencing of 31 wild and cultivated soybean genomes identifies patterns of genetic diversity and selection. Nat Genet. 2010;42(12):1053-U1041.

28. Chen $\mathrm{XQ}, \mathrm{Yu} \mathrm{BJ}$. lonic effects of $\mathrm{Na}^{+}$and $\mathrm{Cl}^{-}$on photosynthesis in Glycine max seedlings under isoosmotic salt stress. Zhi Wu Sheng Li Yu Fen Z Sheng Wu Xue Xue Bao. 2007;33(4):294-300.

29. Li WYF, Wong FL, Tsai SN, Phang TH, Shao GH, Lam HM. Tonoplast-located GmCLC1 and $\mathrm{GmNHX1}$ from soybean enhance $\mathrm{NaCl}$ tolerance in transgenic bright yellow (BY)-2 cells. Plant Cell Environ. 2006;29(6):1122-37.

30. Wong TH, Li MW, Yao XQ, Lam HM. The GmCLC1 protein from soybean functions as a chloride ion transporter. J Plant Physiol. 2013;170(1):101-4

31. Barbier-Brygoo H, Vinauger M, Colcombet J, Ephritikhine G, Frachisse J, Maurel C. Anion channels in higher plants: functional characterization, molecular structure and physiological role. Biochim Biophys Acta. 2000; 1465(1-2):199-218.

32. Nguyen CT, Agorio A, Jossier M, Depre S, Thomine S, Filleur S. Characterization of the chloride channel-like, AtCLCg, involved in chloride tolerance in Arabidopsis thaliana. Plant Cell Physiol. 2016;57(4):764-75.

33. Alvarez-Gerding X, Cortes-Bullemore R, Medina C, Romero-Romero JL, Inostroza-Blancheteau C, Aquea F, Arce-Johnson P. Improved salinity tolerance in Carrizo citrange rootstock through overexpression of glyoxalase system genes. Biomed Res Int. 2015.

34. Brumos J, Colmenero-Flores JM, Conesa A, Izquierdo P, Sanchez G, Iglesias DJ, Lopez-Climent MF, Gomez-Cadenas A, Talon M. Membrane transporters and carbon metabolism implicated in chloride homeostasis differentiate salt stress responses in tolerant and sensitive Citrus rootstocks. Funct Integr Genomic. 2009;9(3):293-309.

35. Tregeagle JM, Tisdall JM, Tester M, Walker RR. $\mathrm{Cl}^{-}$uptake, transport and accumulation in grapevine rootstocks of differing capacity for $\mathrm{Cl}^{-}$-exclusion. Funct Plant Biol. 2010;37(7):665-73.

36. Abbaspour N, Kaiser B, Tyerman S. Chloride transport and compartmentation within main and lateral roots of two grapevine rootstocks differing in salt tolerance. Trees-Struct Funct. 2013;27(5):1317-25.
37. Jossier M, Kroniewicz L, Dalmas F, Le Thiec D, Ephritikhine G, Thomine S, Barbier-Brygoo H, Vavasseur A, Filleur S, Leonhardt N. The Arabidopsis vacuolar anion transporter, AtCLCC, is involved in the regulation of stomatal movements and contributes to salt tolerance. Plant J. 2010;64(4):563-76.

38. Wei QJ, Liu YZ, Zhou GF, Li QH, Yang CQ, Peng SA. Overexpression of CsCLCC, a chloride channel gene from Poncirus trifoliata, enhances salt tolerance in Arabidopsis. Plant Mol Biol Rep. 2013;31(6):1548-57.

39. Lv QD, Tang RJ, Liu H, Gao XS, Li YZ, Zheng HQ, Zhang HX. Cloning and molecular analyses of the Arabidopsis thaliana chloride channel gene family. Plant Sci. 2009;176(5):650-61.

40. Liu Y, Yu LL, Qu Y, Chen JL, Liu XX, Hong HL, Liu ZX, Chang RZ, Gilliham M, Qiu LJ, et al. GmSALT3, which confers improved soybean salt tolerance in the field, increases leaf $\mathrm{cl}$ - exclusion prior to $\mathrm{Na}+$ exclusion but does not improve early vigor under salinity. Front Plant Sci. 2016;7.

41. Shi H, Lee B-h, Wu S-J, Zhu J-K. Overexpression of a plasma membrane $\mathrm{Na}^{+}$/ $\mathrm{H}^{+}$antiporter gene improves salt tolerance in Arabidopsis thaliana. Nat Biotechnol. 2002;21:81.

42. Zhao XF, Wei PP, Liu Z, Yu BJ, Shi HZ. Soybean $\mathrm{Na}^{+} / \mathrm{H}^{+}$antiporter GmsSOS1 enhances antioxidant enzyme activity and reduces $\mathrm{Na}^{+}$accumulation in Arabidopsis and yeast cells under salt stress. Acta Physiol Plant. 2017;39(1).

43. Bergsdorf EY, Zdebik AA, Jentsch TJ. Residues important for nitrate/proton coupling in plant and mammalian CLC transporters. J Biol Chem. 2009; 284(17):11184-93.

44. De Angeli A, Monachello D, Ephritikhine G, Frachisse JM, Thomine S, Gambale $\mathrm{F}$, Barbier-Brygoo $\mathrm{H}$. The nitrate/proton antiporter AtCLCa mediates nitrate accumulation in plant vacuoles. Nature. 2006:442(7105):939-42.

45. Dong CH, Rivarola M, Resnick JS, Maggin BD, Chang C. Subcellular colocalization of Arabidopsis RTE1 and ETR1 supports a regulatory role for RTE1 in ETR1 ethylene signaling. Plant J. 2008;53(2):275-86.

46. Saraiva KDC, de Melo DF, Morais VD, Vasconcelos IM, Costa JH. Selection of suitable soybean EFla genes as internal controls for real-time PCR analyses of tissues during plant development and under stress conditions. Plant Cell Rep. 2014:33(9):1453-65.

47. Schmittgen TD, Livak KJ. Analyzing real-time PCR data by the comparative CT method. Nat Protoc. 2008:3:1101.

48. Schapire AL, Lois LM: A simplified and rapid method for the isolation and transfection of Arabidopsis leaf mesophyll protoplasts for large-scale applications. In: Plant signal transduction: methods and protocols. Edited by Botella JR, Botella MA vol. 1363, 2nd edn. New York, NY: Humana Press; 2016: 79-88.

49. Scala V, Grottoli A, Cigliano RA, Anzar I, Beccaccioli M, Fanelli C, Dall'Asta C, Battilani P, Reverberi M, Sanseverino W. Careful with that axe, gene, genome perturbation after a PEG-mediated protoplast transformation in Fusarium verticillioides. Toxins. 2017;9(6). https://doi.org/10.3390/toxins9060183.

50. Li X, Yang RH, Ma MG, Wang X, Tang J, Zhao XX, Zhang XP. A novel aldehyde reductase encoded by YML131W from Saccharomyces cerevisiae confers tolerance to furfural derived from lignocellulosic biomass conversion. Bioenerg Res. 2015;8(1):119-29.

51. Zhou Q Yu BJ. Accumulation of inorganic and organic osmolytes and their role in osmotic adjustment in $\mathrm{NaCl}^{-}$stressed vetiver grass seedlings. Russ J Plant Physl. 2009:56(5):678-85.

52. Wei PP, Chen DM, Jing RA, Zhao CR, Yu BJ. Ameliorative effects of foliar methanol spraying on salt injury to soybean seedlings differing in salt tolerance. Plant Growth Regul. 2015;75(1):133-41.

Ready to submit your research? Choose BMC and benefit from

- fast, convenient online submission

- thorough peer review by experienced researchers in your field

- rapid publication on acceptance

- support for research data, including large and complex data types

- gold Open Access which fosters wider collaboration and increased citations

- maximum visibility for your research: over $100 \mathrm{M}$ website views per year

At BMC, research is always in progress.

Learn more biomedcentral.com/submissions 